\title{
THE NOVEL CHARACTERISTICS OF PTEROSAURS: BIOLOGICAL INSPIRATION FOR ROBOTIC VEHICLES
}

\author{
S. CHATTERJEE ${ }^{1}$, R. LIND² \& B. ROBERTS ${ }^{2}$ \\ ${ }^{1}$ Museum of Texas Tech University, Lubbock, TX 79409, USA. \\ ${ }^{2}$ Mechanical and Aerospace Engineering, University of Florida, Gainesville, FL 32611, USA.
}

\begin{abstract}
Bioinspiration and biomimetic have led to a variety of robotic designs, especially small autonomous unmanned aerial vehicles for urban environment that have taken cues from birds, bats, and insects. The ease with which these flying animals negotiate confined obstacle-cluttered airspace has long inspired engineers for designing small robots for surveillance and reconnaissance missions. However, one group of extinct flying animals, which flew over the heads of dinosaurs and dominated the Mesozoic skies for 160 million years, have been largely overlooked for designing small aircrafts, partly because they are extinct and their fossils are difficult to study because of preservational deformation. Recently, exquisite pterosaur fossils have been discovered, which provide critical insights into their dynamics. Tapejara wellnhoferi, a pterodactyloid from the Early Cretaceous ( 110 million years ago) of Brazil, provides a platform that is particularly valuable for biomimicry of a robotic vehicle. This pterodactyloid had sophisticated sensor mechanisms for determining its aerodynamics, had a cranial crest that was destabilizing but provided agility, had highly articulated wings that enabled precise shape control, and had the ability to fly, walk, and sail. An initial design for a robotic vehicle is described, which incorporates some of the characteristics of the Tapejara wellnhoferi.

Keywords: Aerial turning, autonomous unmanned air vehicle in urban environment, Biomimetics, Early Cretaceous Tapejara, flight dynamics, forward placement of vertical tail, multimodal locomotion, pterodactylinspired robot, Pterodrone, vertical takeoff and landing.
\end{abstract}

\section{INTRODUCTION}

Urban surveillance and sensor emplacement is an area of interest for both military and civilian applications. In both wartime and emergency disaster situations, authorities need as much information as possible in a short period of time to make good decisions about as to how to proceed to solve the situation. An unmanned aerial vehicle (UAV), commonly known as a drone, is a small aircraft without a human pilot on board. A UAV is an ideal platform to deliver sensors to the area to obtain information by agile maneuvering until a target is identified. UAVs are acquiring an increased level of autonomy as more complex mission scenarios are envisioned. Considerable interest has been taken in the recent years in designing autonomous UAVs to navigate through a dense field of obstacles and maintaining efficiency while sensing. These drones are capable of stealthy and highly maneuverable autonomous flight that can carry cameras, sensors, communication equipment, or other payloads. Autonomous UAVs are intelligent aircrafts capable of performing tasks in the real-world environment without explicit human control over their movements. Some UAVs of Tier I category become so small and light that they can be launched from one's hand and maneuvered through the street at a low altitude and long endurance. These UAVs, known as Ravens, developed by the leading aerospace company AeroVironment for the US Armed Forces, are especially useful in urban areas. The aircraft can fly up to $10 \mathrm{~km}$ radius at an altitude of $150 \mathrm{~m}$ above ground level at flying speeds of 45-97 km/h [1]. It displays real-time videos and images captured by the vehicle's payload cameras. The high level of current interest in UAVs is the result of the nearly simultaneous emergence of their technological feasibility and an array of compelling new military and civilian needs, especially in urban environments. These vehicles have the potential both to remove the risk of loss of human life from aerospace applications and to eliminate the many system requirements

(C) 2013 WIT Press, www.witpress.com

ISSN: 1755-7437 (paper format), ISSN: 1755-7445 (online), http://journals.witpress.com

DOI: 10.2495/DNE-V8-N2-113-143 
necessary to accommodate humans. Thus UAVs can be made more agile to make tighter turns than a human could withstand, made smaller than a size that could carry humans, and filled with many more military payload or sensor systems than the same-sized manned vehicle could carry.

Nature's evolutionary experiments have provided the inspiration for a wide range of flying machines. The recent developments in the study of UAVs for urban environment navigation and sensing have used biological systems for inspiration. Morphing vehicles have taken cues from birds [2], bats [3], and insects [4] for their configuration, materials, flight maneuvers, and sensorimotor system. However, one group of extinct flying animals, the pterosaurs, has been largely overlooked in the design of intelligent UAVs with much better aerodynamic performance than conventional wings and rotors. The pterosaurs show promise as a model for not only a capable flight vehicle, but as a small functional air-ground sea robotic, named Pterodrone, which is about the size of a seagull.

The mission performance for small aircraft is often dependent on the turn radius. Various biologically inspired concepts have demonstrated that the performance can be improved by morphing the wings in a manner similar to that of birds and bats; however, morphing of the vertical tail has received less attention because neither birds nor bats possess a vertical tail. In contrast, pterodactyloids have a large vertical crest on their heads, which could have improved their flight performance to assist in tasks necessary for survival. This paper investigates the flight dynamics of a pterodactyloid Tapejara and analyzes the aerodynamic and weight effects of a pterodactyloid's head on performance. Additionally, aerodynamic interactions between the crest and a pterosaur's wing-sweep morphing capabilities are analyzed. These results are used to design an aircraft model that incorporates a morphing of the vertical tail based on the cranial crest of a pterodactyloid. The flight dynamics of the aircraft model demonstrates a reduction in the turn radius of $14 \%$ when placing the tail over the nose in comparison with the traditional aft-placed vertical tail.

The Pterodrone is a flapping flier with a wingspan of $60 \mathrm{~cm}$ and weighs only $400 \mathrm{~g}$, which provides autonomous surveillance targeting, tagging, and biochemical sensing across a variety of operation areas. It is not a remote-controlled robot. It has an on-board computer that controls its flight. However, Pterodrone is still a prototype and is designed to replicate the flight of pterosaurs but can hide in plain sight. It demonstrates considerable utility to conduct intelligence, surveillance, and reconnaissance over danger zones in urban environments and displays a wide variety of configurations, depending on specific mission requirements. This lightweight small aircraft could be launched in just minutes, by hand, into the air like a model airplane. It can perch on a windowsill by auto-piloting with its retractable legs and can land on building, water, or strategic place. It has a forwardly placed tail that allows it to turn tightly. Pterodrone is programmed for autonomous missions, using the global positioning system waypoint navigation, and can deliver color and infrared imagery to the ground control unit with its charge-coupled device color video and an infrared camera. It can provide day-and-night surveillance at an effective radius of $10 \mathrm{~km}$ or more and has a flight endurance of $1 \mathrm{~h}$ at a typical operating altitude of 30-150 m. Moving beyond mimicry, biologically inspired flying machines such as Pterodrone can be simpler in design yet more powerful in function than their natural analogs such as pterosaurs.

\section{PTEROSAUR CHARACTERISTICS}

\subsection{Anatomy}

Pterosaurs, the extinct volant archosaurs of the Mesozoic that ranged in size from a sparrow to a small aircraft, have captivated paleontologists and aeronautical engineers for more than a century. 
Pterosaur flight is an intriguing topic that stimulates imagination, creativity, and appeals to the scientific and engineering community as well as the general public. Collaborations between paleontologists and aeronautical engineers have a long history since 1914 to unravel the mystery of the flight dynamics of pterosaurs. Pterosaurs were the first radiation of vertebrates that developed active, powered flight. They have a unique wing anatomy unlike that of birds and bats, wherein the forelimb and the hyper-elongated fourth finger formed a single bony spar at the leading edge to support a long and narrow membranous wing that extended along the sides of the body to the legs analogous to the spar of the Indian fighter kite (Fig. 1). The spar is tensioned into a bow in an extended wing position in order to provide greater support for the wing membrane. In contrast to thin, compliant, and uniform bat wing, the skin membrane in pterosaurs was not a mechanically homogenous structure, but had a relatively elastic section in the inner wing (plagiopatagium) and a stiffer semi-rigid outer wing (dactylopatagium); the latter is reinforced by densely packed, radiating rod-like fibers - actinofibrils - that conferred structural integrity and allowed folding and unfolding of the wing like the battens of a sail to reduce the stretch. This unique variable wing structure gives pterosaurs more options for flight than most birds and bats. Pterosaurs had a dense covering of hair distributed over most of the head, body, base of the tail, and upper part of the arms and legs that provided insulation and streamlining of the body surface.

Pterosaur bones were lightly built for flight; they were hollow, pneumatic, and thin-walled tubes reinforced internally by struts. The honeycomb airspaces contribute to the lightweight of the skeleton. Based on the wing and tail morphology, pterosaurs have been traditionally divided into

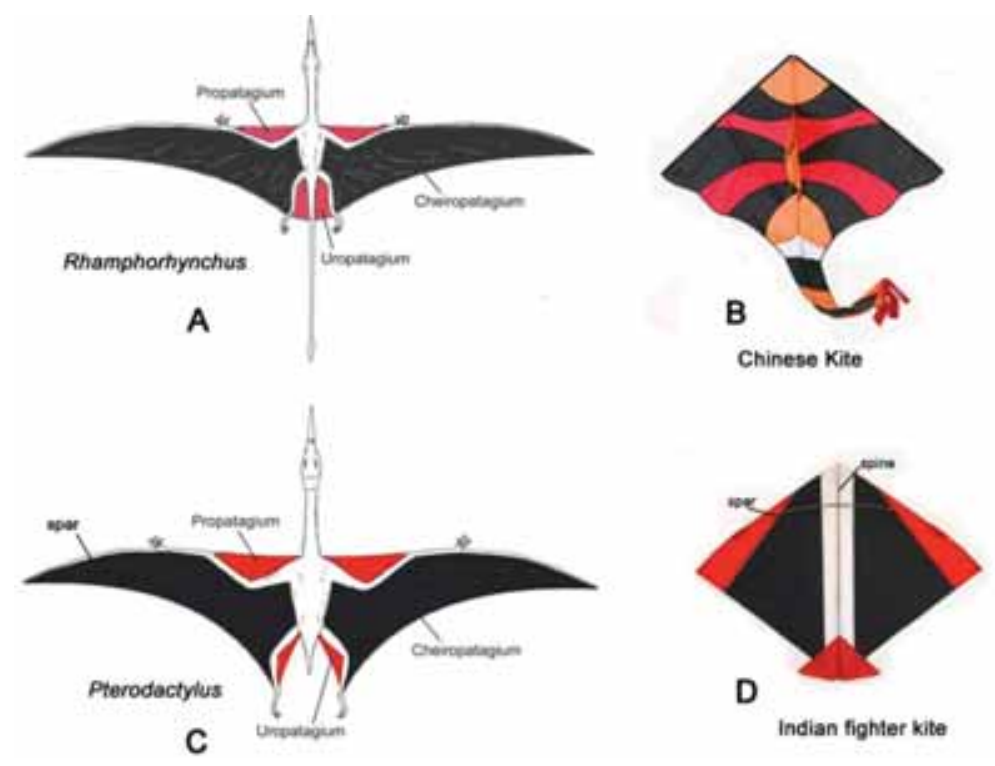

Figure 1: The two main types of pterosaur wing planforms. (A) The typical arrangement of the flight membranes of a primitive 'rhamphorhynchoid' with a long bony tail distinguished by a complete uropatagium stretched between the hindlimbs. (B) A Chinese kite with a long tail for stability. (C) The more derived pterodactyloid lacking a bony tail, in which the uropatagium is split up in the middle, leaving two small crescentic patagia filling the inner angle of the knee. (D) An Indian fighter kite without a tail for maneuverability. 
two groups: the basal, paraphyletic 'rhamphorhynchoids' and the more derived monophyletic pterodactyloids [5]. The 'rhamphorhynchoids' had broad wings with a complete uropatagium between the hindlimbs, and a long bony tail similar to the design of a Chinese kite (Fig. 1). Many of the 'rhamphorhynchoids' were small, about the size of pigeons or gulls with oversized wings. They are the basal group of early pterosaurs with a short skull and neck, a long tail. The bony tails can be very long and stiff with a rudder-like vertical vane on the tip, which perhaps functioned as a dynamic stabilizer in flight. In this configuration of the tail, the flight is stable but less maneuverable. In contrast, the pterodactyloids have a long skull and neck and lost the bony tail. With the loss of the tail, the uropatagium is split in the middle, becomes narrow, so that each leg could move independently to change the geometry of the cheiropatagium like an aircraft's aileron, especially during banking, thus improving the flight performance [6]. Pterodactyloids also developed a huge bony crest on top of the skull probably for sexual display. The location of the cranial crest in front of the center of gravity (CG) would create instability in the yaw axis. The loss of the bony tail and development of bony crest would decrease the static and dynamic stability. This disadvantage comes with a tradeoff. The pterodactyloids became more acrobatic and maneuverable than 'rhamphorhynchoids' but were less stable; instability was probably compensated by the neural control [7] and leg-induced control. The pterodactyloids were designed to take advantage of natural instability in order to produce controlled mobility, a body plan similar to the Indian fighter kite. There appears to be a shift from tail-induced wing control to leg-induced wing control during the evolution of pterosaurs. The crest functioned as a front rudder to make agile turn $[8,9]$.

Unlike birds and bats, the pterosaurs, which were equally sophisticated flyers, have received little attention for creating biomimetic models. This is mainly because, until recently, the available fossil material has not been of sufficient quality to permit an accurate three-dimensional reconstruction of the skeletal anatomy: a prerequisite for a biomimetic model. One of the remarkable pterosaurs is a crow-size pterodactyloid from the Early Cretaceous Santana Formation of Brazil, called Tapejara wellnhoferi with a wingspan of $1.28 \mathrm{~m}$ that possessed an aerodynamic oddity - an enormous vertical cranial crest, partly bony partly membranous that triples the height of the skull [5-7]. The skull of Tapejara is relatively short and toothless with a large sagittal premaxillary crest extending to the posterior end of the skull, an expanded nasoantorbital fenestra that occupies one-third of the lateral surface of the skull, a ventrally inclined tapering rostrum, and a mandibular sagittal crest. The premaxillary crest was lightly built and supported at its posterior edge a flaring membranous structure like a vertical sail, which was reinforced internally by stiff fiber-like networks of cornified epidermis. The fibers in the soft membranous tissue provided the structural framework of the cranial sail that could be traced forward into the bony part of the crest to maximize the strength and stiffness. The semi-rigid cranial sail would be $\sim 16$ times the lateral surface of the premaxillary crest and must have had an aerodynamic effect. Such an elaborate and idiosyncratic design of the cranial crest is probably related to courtship and mating display, but its location ahead of animal's CG appears to be an anomaly in flight design (Fig. 2).

Several novel stabilizing and control surfaces might have compensated for yaw instability and made Tapejara a versatile flyer as it traded off instability for maneuverability. Most likely, the cranial sail functioned as a sophisticated wind sensor and acted as an active stabilizer, such as an automatic feedback control system. It could relay the aerodynamic perturbations to the wing via vestibular apparatus of the inner ear and enhance the aerial turn [4]. Pterosaurs display a wide variety of sensory response systems, such as vision, equilibrium sensing, and mechanosensing along with sophisticated control surfaces in the head crest and wing morphologies that provide a stable controlled flight. We can learn from these animals aeroelastic, flapping wing flight at a low Reynolds number for inspiration and design templates. Tapejara probably fed on small fish and crustaceans while dipping its short and pointed beak during surface swimming [9]. 


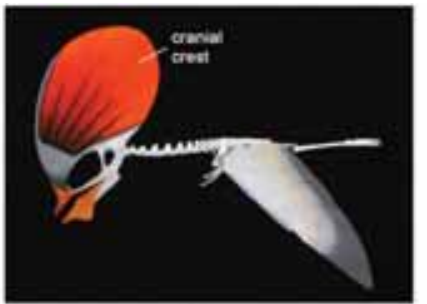

A

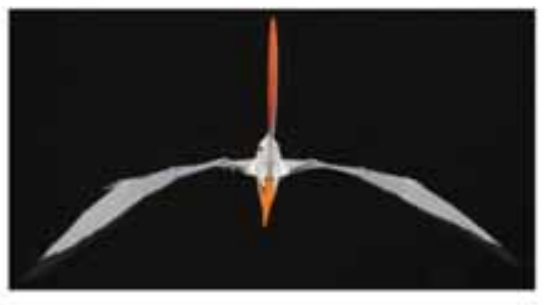

B

Figure 2: The skeletal and soft-tissue reconstruction of Tapejara wellnhoferi with a cranial crest and membranous wings in a flying posture. Tapejara was an Early Cretaceous pterodactyloid from Brazil, the biological inspiration for the Pterodrone. (A) The left lateral view showing a large cranial crest with a soft membrane; (B) the front view.

\subsection{Cranial crest}

Some species of pterosaurs, especially pterodactyloids, had peculiar crests on their skulls. These were very thin, bony plates that varied in the size, shape, and placement on the skull. These cranial crests are one of the 'bizarre-structures' that had intrigued paleontologists for more than a century. Various functional and behavioral considerations of the cranial crests in pterodactyloids have been proposed in the past including sexual display [10, 11], species recognition [12], support for soft tissue extension [13], aerodynamic stability and control [14], attachment area for neck muscles [15], forward rudder [16-18], thermoregulation [17], and airbrake [18]. Although cranial crests may have served more than one function, we can narrow down the range of possible functions; species recognition and sexual selection may be the primary driving force for the evolution of such exaggerated structures in flying animals, which might be co-opted for aerodynamics.

The location of an enormous cranial crest of Tapejara in front of the animal's CG is an aerodynamic oddity (Fig. 2). There is no successful modern aircraft with a vertical fin or rudder for yaw control, which is located so far ahead of the body's CG as is Tapejara's large cranial crest. The problem is the avoidance of inherent instability in yaw of a stiff forward vertical surface. It is simpler (and safer) for the designer to place the control surface for pitch and yaw well behind the CG. The principal explanations of biomechanical functions of the cranial crests of pterodactyloids, such as front rudder and stabilizer, are analyzed here in the context of stability and maneuverability. Possibly Tapejara similar to other pterodactyloids used the crest as a rudder [17] to help it steer and balance, but its placement in front of the CG is anomalous as it would create instability in the yaw axis, as a wind gust from the right would yaw the pterosaur left, thus creating an even larger wind force acting to yaw the animal further. Common sense would dictate that such a forward placement of cranial crest in pterodactyloids along the animal's plane of symmetry could not produce any lift or pitching moment. Why did Tapejara evolve such an enormous crest if it would interfere with its flight performance? Here we explore several possibilities to evaluate the aerodynamic function of the cranial crest to counter the instability in the yaw axis.

Certain long-necked fishing birds, such as magnificent frigatebirds, pelicans, and herons, tucked their heads between their shoulders in flight to bring the heads above the animals' CG [19]. If Tapejara could retract their neck over its shoulder to form an S-shaped curvature and to bring the cranial crest close to the CG during flight, it could solve the apparent yawing stability problem. However, Tapejara similar to other pterodactyloids had a long and stiff horizontal neck that discounts this possibility of head retraction over its shoulder during flight [6]. 
Tapejara developed various strategies to suppress the yaw instability induced by the cranial crest. The most likely control surface to counter the yaw instability appears to be the webbed feet at the back of the CG. Direct articulation of the femur and acetabulum allows one to conclude that a pterosaur could achieve this vertical pedal configuration because of its unusual femur morphology; the spherical head is separated from the shaft by a narrow neck at an angle of $45^{\circ}$ and could be rotated backward and upward without dislocation from the acetabulum to keep the feet in the parasagittal plane. During flight, the webbed feet of Tapejara were aligned vertically as in other pterodactyloids to function as 'twin tail fins' on the aft end of the body that could suppress the yaw instability induced by the cranial crest $[6,16]$.

A twin tail would confer stability and agility in pterodactyloids. Many modern fighter planes use this twin tail configuration to control yaw. The movable webbed feet could also act as additional rudders to enhance the aerial turn and could deflect inward during takeoff to increase the pitching moment. In order to completely counteract the static instability of the head crest, the total area of the two feet would have to be approximately equal to the area of the head and crest. Since the combined pedal area is much smaller $\left(0.0012 \mathrm{~m}^{2}\right)$ than the lateral surface of the skull area $\left(0.07 \mathrm{~m}^{2}\right)$, the dynamic stability is probably restored by an automatic feedback from the crest to the wing.

We have used a computer simulation model to study the flight dynamics of the cranial crest of Tapejara. Our analysis shows a marked improvement in the allowable turning radius of Tapejara when the flight conditions are normalized to a constant drag $[7,8,16]$. The cranial crest could enhance the turning performance, especially at the start of the turn while the wing is also banking rapidly. As expected, the derivatives show the appearance of lateral instability with a forward-placed crest, but the distal parts of the wings analogous to the ailerons were capable of controlling such instability, while the animal could still benefit from the improved maneuverability resulting from unstable dynamics. Apparently Tapejara traded off stability for maneuverability during flight, a recurrent theme in the evolution of both birds and aircraft [7]. The cranial crest could also be used as a forward rudder, which helped Tapejara to make $180^{\circ}$ aerial turns in a distance of their wingspan, where the skull could be swung to the left or to the right at the occipito-vertebral joint $[17,20]$. Once in steady turn the rudder may be returned almost to a neutral position, except that in Tapejara it may also contribute to a dynamic stability with small automatic motions as in straight flight, or it could restore the balance after an aerial turn by an automatic adjustment to restore the dynamic stability similar to the instinctive steering of the front wheel of an unstable bicycle. In some ways, the cranial crest is analogous to the hindwings of butterflies, which are unnecessary for flight but help them to turn quickly to evade predators [21]. The spongy elastic properties of the crest would help dampening the lateral gusts without any structural damage.

\subsection{Control}

Both biological and engineering systems require sensors for controlling locomotion. Pterosaurs possessed certain remarkable sensibilities similar to those of modern birds in relation to intricate the flight using a delicate controlled interaction with a surrounding airflow.

\subsubsection{Neurosensory control}

The central nervous system of a pterosaur consists of the brain, sense organs, the spinal cord, and the nerves. The nerves carry messages from the sense organs, such as nose, eyes, or ears, to the brain through an electrical coding. During flight, the pterosaur's sensory apparatus assessed the environment and conveyed impressions through electric pulses, which streamed to the spinal cord for immediate reaction, or are transferred to the brain for central processing. The neurological basis 
of control holds particular interest in that flight demands on sensory integration, equilibrium, and muscular control are acute. Both neural and mechanical feedbacks play roles in controlling animal flight. The rapid feedback from both mechanical and neural pathways are integrated with the information from the eyes, ears, and nose, and other sensing organs used to control the overall flight motion of the animal and provide a robust operation in a wide variety of environments. Here, we investigate the control of flight in pterosaurs using the neurosensory, biomechanical, and computer simulation data.

The brain of pterosaurs sheds new light on their adaptation to aerial lifestyle. The endocasts reconstructed from a CT scan show that the brains similar to that of modern birds seems to have filled the cranial cavity almost completely; thus the endocast provides a broad picture of the size and shape of the brain [22]. Pterosaurs have a full repertoire of well-developed senses. The brain is essentially a thick-walled tube, differentiated into three segments from front to back in an avian fashion: the cerebrum (forebrain), the optic lobes (midbrain), and the cerebellum (hindbrain) (Fig. 3). The forebrain is responsible for complex behavioral instincts and instructions, sensory integration, and learned intelligence. It includes the olfactory bulbs and cerebral hemispheres (cerebrum). The reduced olfactory lobes indicate that olfaction was probably poorly developed in pterosaurs similar to modern birds. However, a recent study suggests that birds with small olfactory bulbs routinely use olfaction in their
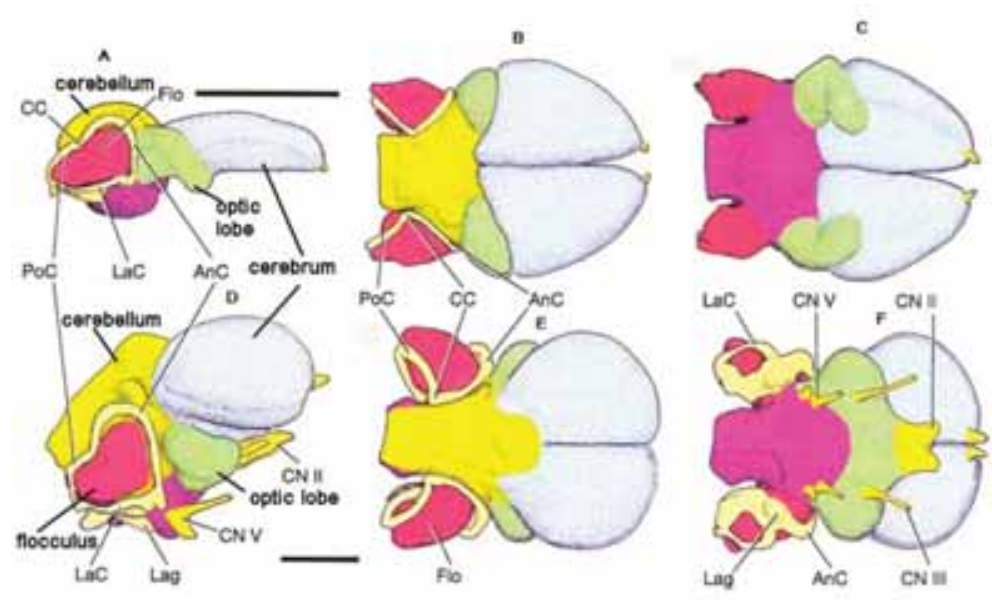

Figure 3: Digital endocasts and labyrinths of brains of pterosaurs reconstructed from the CT scan. Top, a basal pterosaur Rhamphorhynchus muensteri (A-C) and bottom, a derived pterodactyloid Anhanguera santanae (D-F) in the right lateral, dorsal, and ventral views. One can see the progressive enlargement of the three components of the brain from the basal pterosaur to pterodactyloid, which might be linked to the loss of the bony tail and compensated by neural development for stability and maneuverability. Note the large flocculus in the vestibular apparatus in the inner ear region, which functioned like a gyroscope for balance and coordination during flight. Abbreviations: AnC, anterior semicircular canal; CC, crus communis; CN II, cranial nerve II (optic nerve); CN III, cranial nerve III (occulomotor nerve); CN V, cranial nerve V (trigeminal nerve); Flo, flocculus (cerebral auricle); LaC, lateral (horizontal) semicircular canal; Lag, lagena; optic lobe (tectum); and PoC, posterior semicircular canal (modified from [22]). 
daily activities. Perhaps the large nasofrontal opening in pterosaurs indicates that the sense of smell might have better developed than once was thought. The midbrain includes the optic lobes and chiasma. Large eyes and well-developed optic lobes of the midbrain provide excellent vision. Pterosaurs lived in an aerial world that was dominated by sight and sound. The hindbrain includes the cerebellum and medulla, the latter linking the spinal cord and the peripheral nervous system to the major control systems of the brain. When we compare the brain architecture between basal pterosaurs, such as Rhamphorhynchus, and derived pterodactyloids, such as Anhanguera, the enlargement of each component of the brain - cerebrum, optic lobes, and cerebellum - are apparent. The cerebral enlargement indicates integration of the senses and enhanced intelligence in pterodactyloids. The forebrain is considerably enlarged for processing sound, touch, and sight, and to adjust the behavior to new situations. The highly enlarged cerebellum in pterodactyloids along with the large floccular recess indicates improvement in balance, coordination, and muscular coordination and proprioception (the positional equilibrium), all important to flying animals.

\subsubsection{Vision}

Pterosaurs were highly visual and diurnal animals and heavily dependent on the vision for directional cues. The visual resolving power of pterosaurs was greatly enhanced, as is evident by the enlargement of the optic lobes - the major site for visual processing center in the brain. Moreover, the large orbits indicate that the presence of large eyes, which were positioned frontally, resulted in a broad, overlapping vision that provided keen sight, sharp images, and possibly excellent color perception, if the head crest was used for sexual display. The flight was primarily guided by a vision that provides spatial information at sufficient speed and a resolution to guide the flight. A pterosaur could gain more information about its surroundings through its eyes than through all its other sense organs together.

\subsubsection{Equilibrium sensing}

Next to vision, the sense of hearing and equilibrium is also well developed in pterosaurs. The inner ear of pterosaurs, in addition to sensing sound, contains gravity and rotation sensors in the form of semicircular canals. The vestibular apparatus containing three semicircular canals, which are oriented roughly in the three planes of space, functions as a well-developed system for sensing the rotational acceleration and equilibrium similar to a gyroscope during flight. The large vestibular organs in pterosaurs provide body information that, perhaps with wing muscle load sensing and probably with the input from vision motion sensing, allow for a stable controlled flight. The enormous flocculus at the center of the canalicular system has an important neural integration with the vestibular system, the eye muscles, and the neck muscles for stabilizing gaze without blurring vision during maneuvers [22]. Pterosaurs had a remarkable capacity to steady their head with their stiff neck as the body underwent dramatic oscillations during flight. Using the orientation of the semicircular canals, we estimated the head posture of two groups of pterosaurs. In basal 'rhamphorhynchoids' the head was oriented in a horizontal manner, but in pterodactyloids, the head was downturned $\sim 40^{\circ}$, which is somewhat analogous to the nose of a Concord airplane that allowed for a less obstructed view and greater overlapping of a binocular vision (Fig. 4). The stable cockpit of the head provides sophisticated sensory mechanisms for flight control with a complex feedback system from the wing. Similarly, hearing acuity was well developed as revealed from the endocast of the inner ear with an elongated lagena. Refined hearing and vocal behavior might have played an important role in pterosaur activities, such as communication, alerting others of impending danger, mating, the care of young, and social behavior. The pterosaurs were increasingly dependent on sight and sound, and less on smell - as is apparent from their reduced olfactory lobes. 


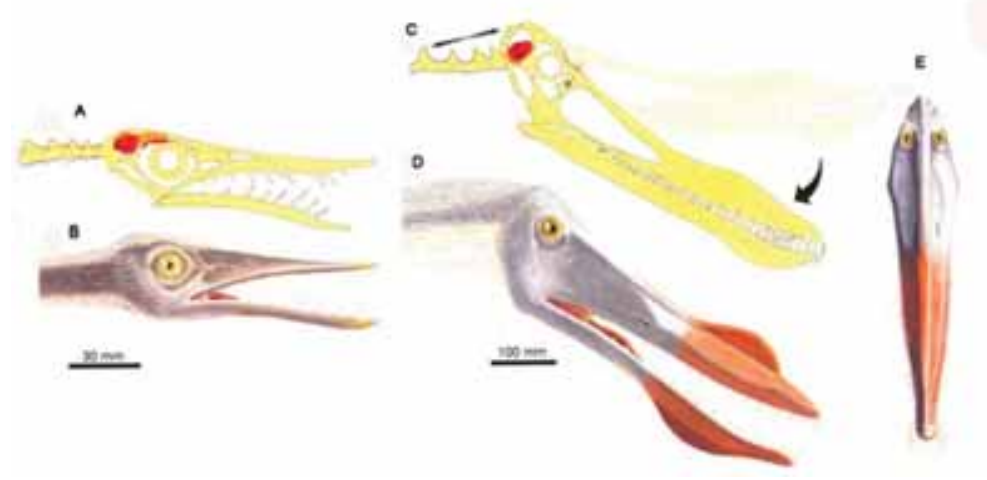

Figure 4: The skull and postures of pterosaurs reconstructed from the horizontal alignment of the lateral semicircular canal of the inner ear. (A and B) The side view of a 'rhamphorhynchoid' skull reflects the horizontal attitude of the head during the flight. (C and D) The side view of a pterodactyloid skull such as Anhanguera during the flight, where the head was oriented $\sim 40^{\circ}$ downturned that allowed a less obstructed view and a greater overlap of a binocular vision. (E) The anterior view of the Anhanguera skull with a downturned head posture [22].

\subsubsection{Sensing airflow}

Sensing the flow of air over the body can be useful information to a flyer for finer adjustments of wings to maintain its intended flight direction. It is likely that a pterosaur's skin possessed sense endings, much like those of bats, which pick up stimuli interpreted by the brain as touch, pain, heat, and cold. Similar to insects and bats, pterosaurs were extremely sensitive to mechanical stimulation. Included among the senses of mechanoreceptors are tactile reception, equilibrium (or balance), and detection of barometric pressure. They had mechanoreceptors in the form of hairs, which are pressure-sensitive sensors scattered all over the body. The cranial crest might have some sophisticated sensory functions to barometric pressure during flight. A part of the clue comes from Thalassodromeus, another sympatric Santana tapejarid that shows a complex network of vascular channels on the bony surface of the cranial crest [18]. We noticed similar vascular channels on the premaxillary crest of Tapejara. Perhaps the enormous cranial crest with its soft-tissue sail of Tapejara was richly supplied with the networks of nerves and blood vessels and was covered with hair, which acted as a large wind sensor like a mechanoreceptor to sense the local conditions of pressure, temperature, and wind direction and respond to them very rapidly like an autopilot device. These abilities suggest sensitivities in barometric pressure. Most likely, the skin covering the soft part of the head crest had a coat of hair similar to the wing membrane that functioned as mechanoreceptors (Fig. 2). The head crest with hair covering was constantly exposed to airflow during flight and might have played a role in the control of pterosaur flight. Combined with the acute vision of the animal, this wind sensor could function as an active stabilizer to sense tiny perturbations in airflow on a much finer scale and correct them instantly. Active stabilization requires a sophisticated nervous system and reflexes to maintain the animal's heading to the flight. The soft tissue-crest was probably connected to the vestibular system of the inner ear, a well-developed equilibrium-sensing device such as a gyroscope, by the neural circuit of the vestibulo-ocular reflex [22]. If the turbulence was large, Tapejara could relay the aerodynamic information via the vestibular system to the smart wings to 
adjust and control the flight attitude. The wings equipped with various control systems (discussed later) would respond very rapidly to correct the disturbances through localized contraction and relaxation of muscle fibers within the membrane [20,22]. Dynamic autopilot controls of the cranial crest might have compensated the static instabilities of Tapejara.

The wing membrane of pterosaurs was covered with hairlike structures on both dorsal and ventral surfaces, which might have acted as mechanoreceptors similar to those of insects [22], birds [23], and bats [24]. Perhaps, pterosaurs could sense the speed and direction of the airflow over the wing with the help of hairlike structures. The tactile senses on hindlimbs and tail would also be valuable for downwash - flow of air forced downward by the wings. Such information is equivalent to sensing the amount of lift produced by the wing. These tactile receptors associated with these hairs were possibly involved in sensorimotor flight control by providing the aerodynamic feedback similar to those of insects, birds, and bats. The feedback responses will direct muscles to alter the wing shape to an optimal position. The enlarged flocculus might have acted as an autopilot device to process proprioceptive and other sensory information from the wing that stretched between the limbs, as well as with limb joint themselves, thus having a more direct impact on the flight control $[25,26]$. In pterosaurs, the neural canal is highly enlarged, indicating the importance of spinal cord in locomotion. Short neural circuits of the spinal cord mostly controlled wing and leg movements that carried the neural messages to the brain stem, the cerebellum. The spinal cord assesses, reacts, and conveys sensory information to and from the major nerves and the brain. Vision, equilibrium sensing, and airflow sensing were apparently used at all levels in pterosaurs as a flight control system.

\subsubsection{Spinal cord}

The posture and locomotion in tetrapods are controlled by a variety of motor centers in the brain and spinal cord. The motor circuits that control locomotion are commonly referred as central pattern generator (CPG), a neural network that is capable of generating an organized pattern of motor activity independently of sensory outputs [27]. The cerebellum is responsible for the fine control of locomotion, aided by CPGs that produce alternating sequences of flexion and extension in various limb muscles. In all tetrapods, the spinal cord, the large nerve trunk running from the base of the brain to the tail, shows two distinct enlargements in the shoulder and hip regions for controlling limb movements. The spinal CPG in walking and flying vertebrates is a distributed network with centers at the cervical and lumbar levels that control the forelimb (wing) and hindlimb, respectively. The locomotor CPGs function autonomously to generate a repetitive pattern of the oscillatory motor activity. Many limb movements are composed of alternating flexions and extensions. However, the underlying spinal network mechanisms remain poorly defined. When a tetrapod moves, the brain does not control the actions solely the spinal cord serves as the local 'control and command' centers to generate the rhythmic and axial limb movements. The spinal cord uses network mechanisms similar to those used in the brain and, in essence, acts as the brain's messenger.

We can speculate the function of the spinal cord of pterosaurs from their close relatives, birds. The neural canal in each vertebra in pterosaurs is highly enlarged relative to the centrum, presumably indicating a well-developed spinal cord for a high demand for nerve signal traffic. The neural canal shows an increased diameter in the cervical and lumbar regions, which might be linked to locomotor control of both wings and the hindlimbs. The flow of neural information to and from the wing and the brain apparently increased for the flight as well as hindlimb innervations for terrestrial locomotion. As in other vertebrates, the spinal cord in pterosaurs probably gave off paired spinal nerves, each with two roots, a dorsal sensory and a ventral motor roots. There are two distinct enlargements in the spinal cord in the cervical and lumbar regions, each associated with nearby brachial plexus and lumbosacral plexus for controlling the sensorimotor system of the wings and legs, respectively (Fig. 5). In birds, the 


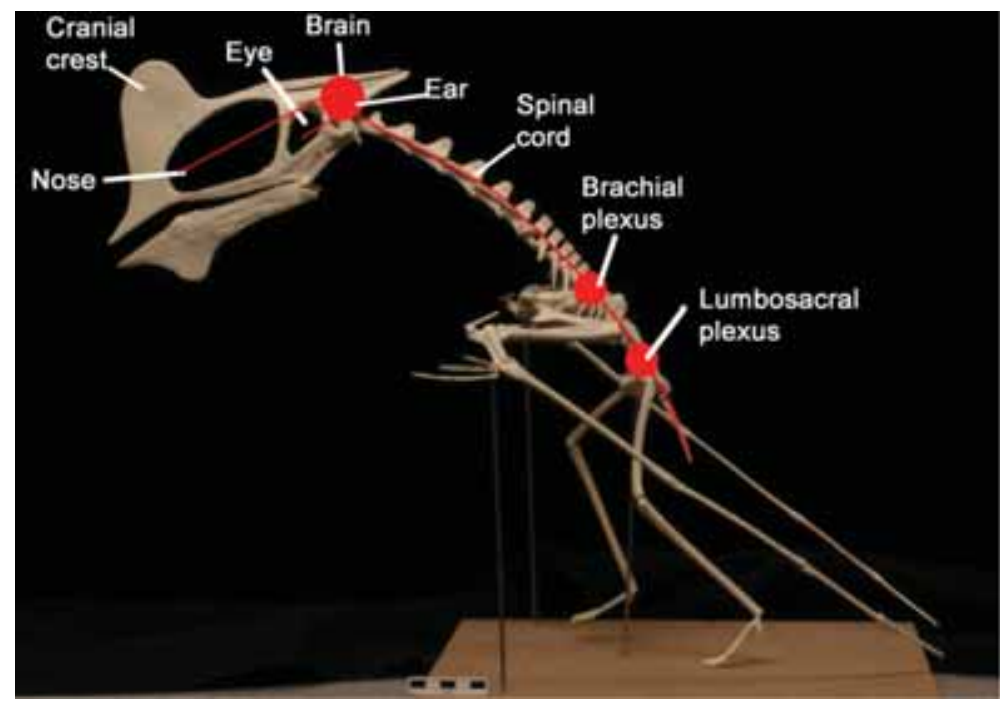

Figure 5: A skeleton of Tapejara showing the central nervous system and the distribution of sensorimotor architecture for neural control. Brachial plexus and lumbosacral plexus, the locomotor central pattern generators (CPGs) in the spinal cord, are responsible for the autonomous movement of the wings and hindlimbs, respectively. In Pterodrone, various sensors could be placed in these strategic positions to simulate the locomotion of pterosaurs.

brachial plexus is more expanded than the lumbosacral plexus because the movement of the wings and hindlimbs need not to be coordinated. The birds use two independent and specialized methods of locomotion: flying in the air with their wings and walking on the ground with their hindlimbs. Because of a nearly horizontal orientation of the body and the location of hindlimbs posterior to the CG of the body, the birds' bipedal locomotion needs special control of balance. The lumbosacral plexus of birds houses a large glycogen body, a structure of unknown function. Recently, it has been suggested that lumbosacral plexus probably functions as an additional sense organ of equilibrium in addition to cerebellum, which is involved in the control of walking. In contrast, pterosaurs similar to other quadrupeds coordinated the movements of the wings or forelimbs with the hindlimbs during quadrupedal locomotion; but during takeoff, landing, and running pterosaurs, they would assume bipedal posture. During flight, the hindlimbs of pterosaurs were passive and decoupled from wing movements as in birds. In designing Pterodrone, we follow the quadrupedal posture during terrestrial locomotion, which appears to be a more stable configuration for modeling.

\subsection{Articulated, flexible wings}

Similar to any aircraft, an animal capable of active flight must possess an integrated control system not only to steer but also to improve its flying capabilities and navigate complex maneuvers. The long, narrow, and slender wings of pterosaurs show various control systems. Perhaps, the yaw instability of pterodactyloids became an advantage with a parallel increase in the efficiency of control systems that allowed agile maneuvering such as turning, banking, climbing, diving, takeoff, and landing. Pterodactyloids, similar to a modern tailless aircraft, had most of its control surfaces on 
their main wing membrane. With the loss of the tail, the uropatagium had severed its connection with the tail, allowing the hindlimbs move independently to control the cheiropatagium, thus improving the flight performance [6]. With the loss of the tail, pterodactyloids became more acrobatic and maneuverable than 'rhamphorhynchoids' but became less stable, which was probably compensated by the neural control [7].

A pterosaur's wing looks very strange to anyone accustomed to aircraft wings, because the spar has four joints in it, shoulder, elbow, wrist, and knuckle joints, which are used to adjust both the span and the area of the wing. The elbow, wrist, and knuckle joints are hinges, which allow movement in only one plane, whereas the shoulder joint permits a complex movement of the wing as a whole, up and down, forward and backward. Pterosaurs had a unique wing anatomy unlike that of birds and bats where the forelimb and the hyper-elongated fourth finger formed a single bony spar at the leading edge to support long and narrow membranous wing that extended along the sides of the body to the legs. Similar to the modern tailless aircrafts, pterosaurs had all their control surfaces on their main wing membrane, which was controlled by the forelimbs and hindlimbs, as well as by the tail in basal forms. They had high-aspect-ratio wings similar to those of the modern seabirds. These wings are long, narrow, flat, and pointed with low wing loading and low cruising speed, which are efficient for soaring in open airspace by exploiting updraft [20]. The wings were extremely flexible at various joints so that they could morph their shape and position instantly to best suit the changing flight conditions. They could flap one wing more forcefully than the other or change the angle of flapping between the two wings, called thrust vectoring to monitored changes in flying conditions. Pterosaur wing bones possess many more independently controllable joints, such as metacarpal and pteroid segments, than those of birds and bats, which were integrated to produce complex and functionally dynamic wing conformations. Moreover, the wing finger could be folded and extended automatically without much muscular effort as it was coupled with the elbow joint [28]. This ingenious design enabled the pterosaurs to fold and conceal its wings against its body when not in use or changes the wingspan to reduce drag and increase the speed during flight when swept back.

Tapejara could be used as a model to identify various control surfaces of pterodactyloids. Tapejara had a wide variety of control surfaces for steering and maintaining its balance during flight by morphing wings, a general theme among all Pterodactyloids, where the wing was controlled by the forelimbs and hindlimbs. A comparison between an unpowered glider and Tapejara shown in the right-hand turns in a thermal updraft identifies several analogous control surfaces (Fig. 6A and B). Ailerons, the movable surfaces on the aircraft wing trailing edges near the tips, are deflected in the opposite directions for roll control in turns. Large deflections are needed only to initiate or make quick changes in turns. In Tapejara, differential twisting or washout in both wingtips would function like ailerons. Tapejara had a flatter wing camber than birds for maximum lift [8, 20], but its flight membrane could be controlled and morphed by its pteroid bone, short tail, and hindlimbs. The aircraft often have additional high-lift slats or adjustable droop along the wing leading edge, and Tapejara's flexible pteroid bone [29] could support the outboard end of a leading edge 'slat' along the propatagium extending to the body. As jumbo jets and other large modern aircraft approach an airport to land, pilots deploy flaps on the leading edges of the wings this allows the plane to fly at much lower speeds without stalling. The discovery of such a technology improving the safety during takeoff and landing has been a key factor in the development of modern aviation. Apparently pterosaurs deployed a wing flap on the front edge of the wing just as jumbo jets do. The orientation of pterosaur's flexible pteroid bone is controversial. Either it was directed forward, or it was oriented medially in a more stable position. No doubt, pterosaur's flexible pteroid bone served to move the propatagium up and down to change the camber and the wing's angle of attack and support the outboard end of a leading edge flap. The cambered propatagium would facilitate not only during 


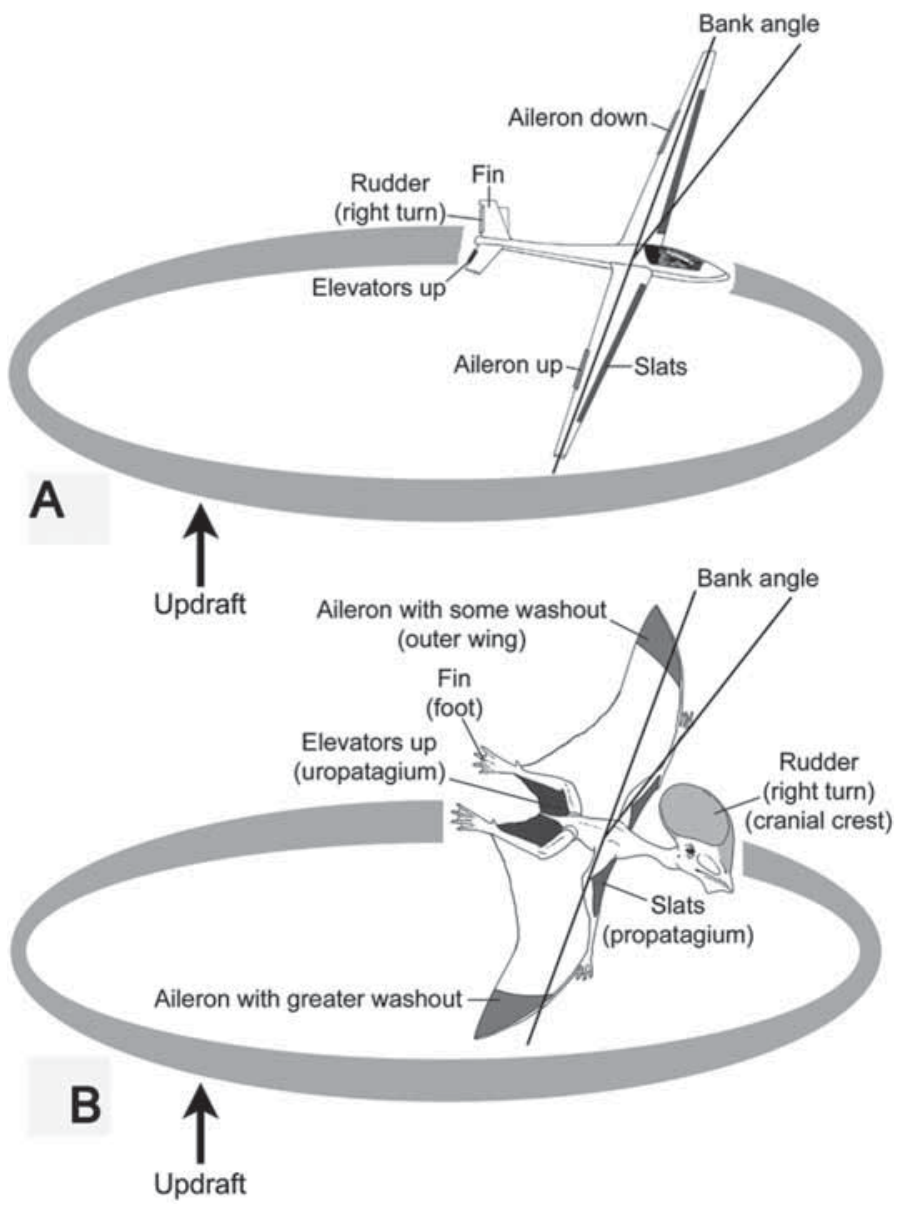

Figure 6: The stability and control surfaces of Tapejara compared with those of a glider. (A) Aerial turn of a glider. (B) Aerial turn of Tapejara. The cranial crest of Tapejara was analogous to the vertical tail that acted as a wind sensor and a forward rudder during aerial turn. The forewing could morph its shape and change the camber similar to the slat of an aircraft. The distal part of the outer wings, reinforced by a bundle of actinofibrils, was capable of a structural twist in relation to the inner wings and functioned similar to ailerons to change the roll axis during an aerial turn. Similarly, the uropatagium could be moved up and down by the femur to change the pitch axis analogous to the function of elevators of an aircraft. The webbed feet functioned as 'twin tail fins' to suppress the yaw instability and function as an additional rudder [30].

takeoff by producing high lift but also during landing as it acted as an airbrake to increase drag and reduce the stalling speed [29]. The leading edge propatagium acted as a high-lift device, increasing the lifting force of the wing at low speeds and high angle of attack, delaying stall and affording the pterosaurs increased control during landing and other maneuvers.

The vertical spreading webbed feet could act not only as twin tail fins to counteract any tendency to yaw but also as a posterior rudder for turning [6]. Since Tapejara's 'flying wing configuration' had 
no horizontal tail surface, pitch control would have been possible by vertical deflection of the uropatagium or by adjustment of the long trailing legs. Wing morphing and sensorimotor architecture make pterodactyloids more agile and maneuverable than bats and birds, especially at very low speeds.

In addition, the wings of pterosaurs were extremely flexible at various joints so that they could morph their shape and position instantly to best suit the changing flight conditions. The aeroelastic behavior of the skin membrane in pterosaurs was anisotropic, with a relatively elastic section in the inner wing and a stiffer semi-rigid outer wing; the latter is reinforced by densely packed, radiating rod-like fibers, called actinofibrils that conferred structural integrity preventing wing from bellowing and tearing in flight $[20,28-30]$.

The wing finger could be folded and extended automatically without much muscular effort as it was coupled with the elbow joint [28]. This ingenious design enabled the pterosaurs to fold and conceal its magnificent wings against its body when not in use (Fig. 7). The skin membrane consisted

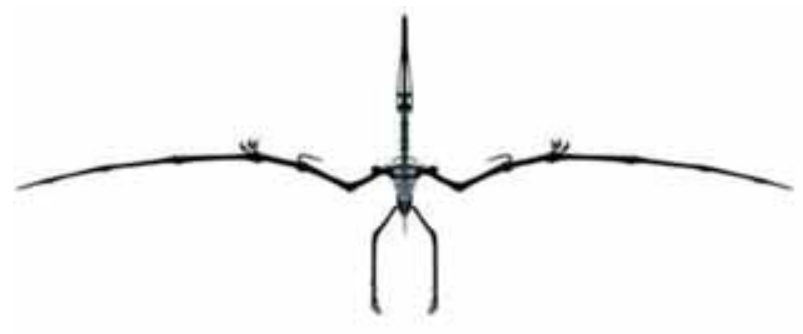

A

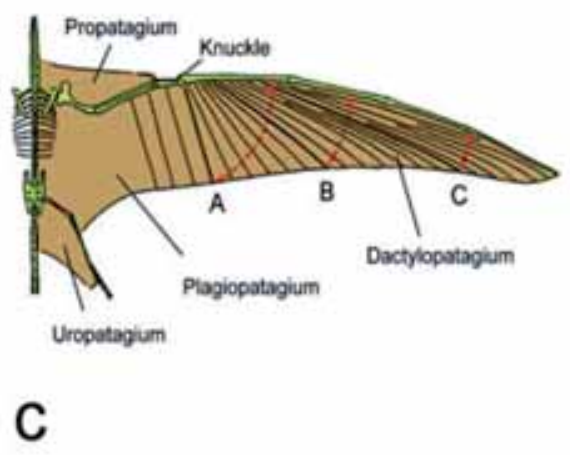

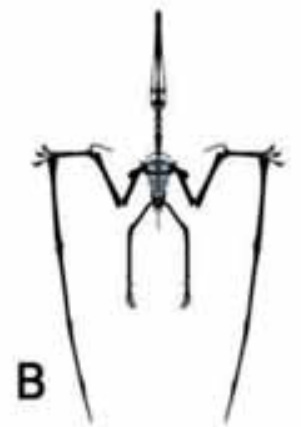

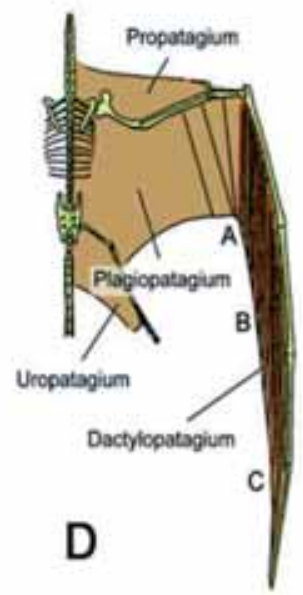

Figure 7: The flexible wings of pterosaurs. (A) The wing bones in a maximum extension position. (B) The wing bones in a maximum flexion position at the knuckle joint to reduce the span. (C and D) The unfolding and folding mechanisms of the wings. The wing membrane, especially the outer wing membrane or dactylopatagium, is reinforced by a system of fine parallel fibers, called actinofibrils to maximize the strength and stiffness required during flight. The actinofibrils provide the structural integrity and prevent bellowing of the membrane during flight; they allow compact folding of the wing during walking [20]. 
of a composite three-layered structure in cross section, with an actinofibril layer at the top, a muscle network layer at the middle, and a complex blood vessel layer at the bottom. The latter feature suggests that the wing membrane may have been an important site for shedding excessive heat. Moreover, the actinofibrils might have created a corrugated structure on the epidermis similar to the vanes of a radiator to cool off the wings.

\section{FLIGHT DYNAMICS OF TAPEJARA}

Various flight parameters such as wingspan, body length, skull length, and skull height were calculated directly from this cast (Fig. 2 and Table 1). To analyze the flight performance of Tapejara, we used two computer algorithms, ANFLTPWR (animal flight power) and ANFLTSIM (animal flight simulation), which are based on the streamtube model, first proposed by Prandtl \& Tietjans [31] and developed by helicopter designers [32] and adapted to animal flight [20, 33]. It avoids the zero-speed problem by making the assumption that a cylindrical tube of air having a cross-section area (A) with the diameter approximately equal to the wingspan (b), or a rotor at flight speed (V), is deflected downward through an angle $(\theta)$, which can vary from $90^{\circ}$ in hovering at zero speed to a small angle in cruising and high-speed flight. The flight power is estimated to be the change in the kinetic energy flow in the streamtube from far upstream to far downstream, which is required to balance the lift and aerodynamic drag. In all cases, the body and wing drag coefficients are computed as functions of the Reynolds number. The small size of Tapejara with its long and narrow wings, high aspect ratio, and low wing loading were adapted for low-speed flights including flapping, thermal/slope soaring, and controlled landing [20,33].

\subsection{Powered flight}

A key to understanding the biomechanics of powered animal flight lies in the margin between the power required for steady flight and the mechanical power available. We have used empirical methods to calculate the maximum available power from the body mass of Tapejara. It is important to note that this is based on a conjecture that the maximum aerobic metabolic rate and muscle efficiency of pterosaurs is similar to that of extant birds, as they share similar physiology. The continuous available power has been estimated from many measurements of metabolic rates of birds and other vertebrates, where the basal metabolic rate is $20 \mathrm{~W} / \mathrm{kg}$ of the body weight [33]. The conversion efficiency from metabolic energy to mechanical power was assumed to be 20\% [34].

Using ANFLTPWR we generated the power curves for Tapejara (Fig. 8A) where the U-shaped curve, analogous to that of aircraft and helicopters, is the power required for a steady level flight. Its left-hand arm is mainly the penalty that must be paid for the production of lift, at low airspeed, and the

Table 1: The aerodynamic data of Tapejara wellnhoferi and Herring Gull.

\begin{tabular}{lcccccccccc}
\hline & $\mathrm{M}$ & $\mathrm{WA}$ & $\mathrm{WS}$ & $\mathrm{AR}$ & $\mathrm{BL}$ & $\mathrm{SR}$ & $\mathrm{CR}$ & $\mathrm{WL}$ & $\mathrm{P}_{\text {avail }}$ & $\begin{array}{c}\mathrm{CS} \\
(\mathrm{Wm} / \mathrm{h})\end{array}$ \\
Species & $(\mathrm{kg})$ & $\mathrm{a}\left(\mathrm{m}^{2}\right)$ & $\mathrm{b}(\mathrm{m})$ & $\mathrm{A}=\mathrm{b}^{2} / \mathrm{S}$ & $1(\mathrm{~m})$ & $\mathrm{b} / 1$ & $\mathrm{c}_{\mathrm{o}} / 1$ & $\left(\mathrm{~N} / \mathrm{m}^{2}\right)$ & $(\mathrm{W})$ & $(\mathrm{km})$ \\
\hline Tapejara wellnhoferi & 0.42 & 0.29 & 1.28 & 5.65 & 0.23 & 5.56 & 1.0 & 14.2 & 5.59 & 27 \\
Larus argentatus & 1.15 & 0.22 & 1.47 & 9.73 & 0.32 & 4.59 & 0.6 & 51 & 11.0 & 44 \\
\hline
\end{tabular}

$\mathrm{AR}$, aspect ratio; $\mathrm{BL}$, body length; $\mathrm{CR}$, chord ratio; $\mathrm{CS}$, cruising speed; $\mathrm{M}$, mass; $\mathrm{P}_{\text {avail. }}$, aerobic power available; SR, spanness ratio; WA, wing area (A); WL, wing loading; and WS, wingspan. Units: kg, kilograms; m, meter; N, Newton, W, watt; and km/h, kilometer/hour. 

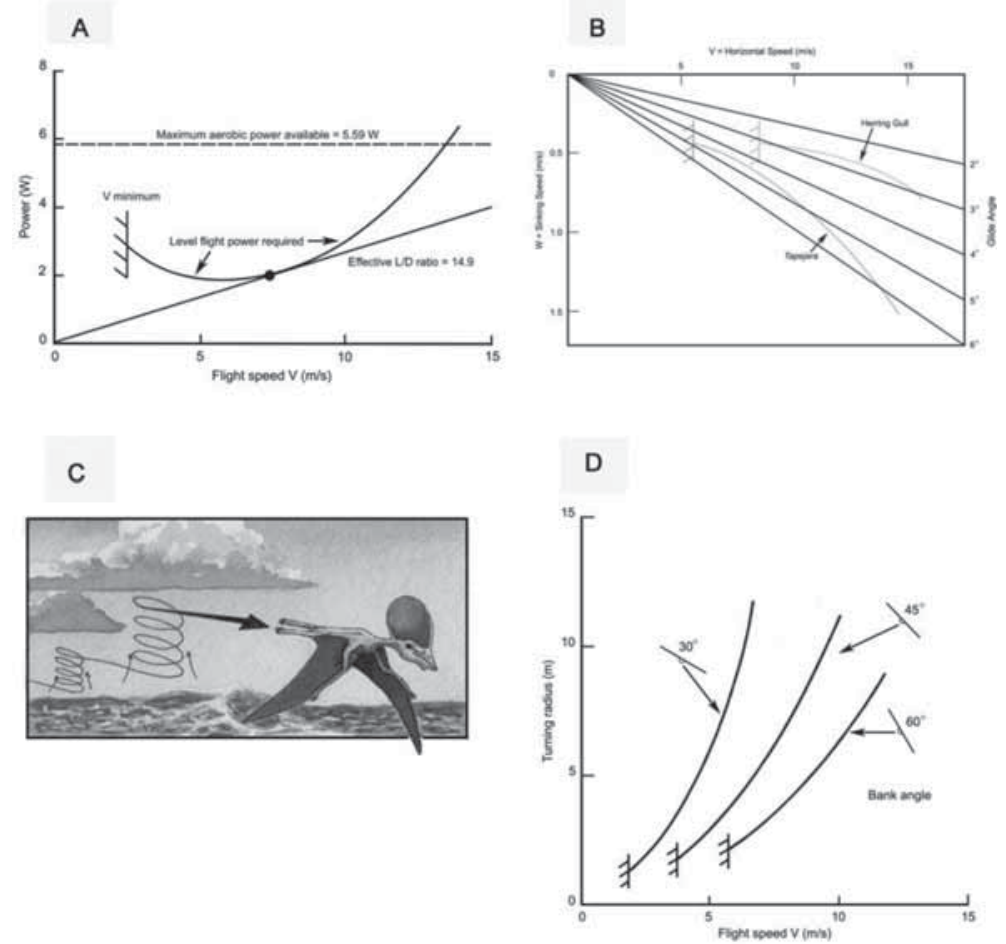

Figure 8: The flight performance of Tapejara. (A) In the power curve the horizontal line represents the estimated maximum continuous power available $(5.59 \mathrm{~W})$ and the U-shaped curve represents the power required for a steady level flight (a minimum of $2 \mathrm{~W}$ ). Because there is wide gap between these two power curves that intersect, Tapejara has enough power for flapping flight with a high degree of maneuverability. (B) The glide polar of Tapejara compared with the Herring gull of a similar size and wingspan. Tapejara was an efficient glider with a minimum glide angle slightly steeper than that of the Herring gull, but approximately with the same minimum sinking speed. (C) Tapejara could exploit marine thermals for long-distance travel during foraging. (D) During thermal soaring the wings of Tapejara must be banked, but while increasing bank angle can tighten the turn, airspeed must increase to avoid stalling in high g-turns [30].

rising right-hand arm shows the cost of aerodynamic friction and body pressure drag. The low-speed end of the curve ends at an estimated power-on stall speed of $\sim 2.0 \mathrm{~m} / \mathrm{s}$, but this is subject to some uncertainty regarding flapping-wing control in near hovering flight. In the power curve, the horizontal line represents the estimated maximum continuous power available $(5.59 \mathrm{~W})$, assuming flight muscle mass comparable with the average percent of living seabirds, and the U-shaped curve represents the power required for a steady level flight (a minimum of $2 \mathrm{~W}$ ). Because there is a wide gap between these two power curves that intersect, Tapejara has enough power to be capable of flapping flight, permitting high maneuverability. Similar to most small flyers, Tapejara has a large excess power available above the power required for steady flight over a fairly wide speed range, which would give the animal good power-on agility. The most efficient cruising speed occurs at $\sim 7.5 \mathrm{~m} / \mathrm{s}$ ( or $27 \mathrm{~km} / \mathrm{h}$ ). For high-speed flight, the wings would sweep back and change the shape to reduce drag. 


\subsection{Gliding flight}

The long and narrow pterosaur wings with a high aspect ratio were adapted for gliding and soaring to a low-speed flight similar to modern seabirds, especially for thermal/slope soaring [35]. We have tabulated the various aerodynamic data of Tapejara and Herring Gull for performance analysis (Table 1). We used ANFLTSIM [20,33] to calculate the gliding performance of Tapejara and compare it with that of the Herring Gull (Larus argentatus) of similar size and wingspan. The gliding performance of Tapejara is shown in a polar curve (Fig. 9B), where the minimum glide slope of the Herring Gull is close to $3^{\circ}$. In comparison, Tapejara's flattest glide slope is $\sim 4.3^{\circ}$. However, because of its lower wing loading, Tapejara's estimated minimum sinking speed $(0.43 \mathrm{~m} / \mathrm{s})$ is slightly less than that of the Herring Gull $(0.46 \mathrm{~m} / \mathrm{s})$ and it thus appears to be better adapted to low-speed soaring.

\subsection{Soaring flight}

Tapejara could make use of rising air in the same manner as seabirds over the windward slopes of the Araripe cliffs. Using ANFLTSIM we have calculated the sinking speed of Tapejara, which is $0.43 \mathrm{~m} / \mathrm{s}$. A moderate wind blowing at $20 \mathrm{~km} / \mathrm{h}$ along a $10^{\circ}$ slope will have a vertical component of $\sim 1 \mathrm{~m} / \mathrm{s}$, which is sufficient to keep Tapejara aloft. Since the sinking speed of Tapejara is less than the velocity of the rising air caused by the upward deflection of the wind over the cliff, Tapejara would be able to remain airborne indefinitely without flapping its wings.

Many seabirds such as Herring gulls and frigatebirds ride on thermals along the equatorial belt for hundreds of kilometers exploiting the few wind energy [35-37]. The paleoposition of Araripe Basin during the Early Cretaceous along the equator exerted a tremendous influence on the climate and wind circulation pattern over the cliff face of the Araripe Basin to generate thermals and slope lift updrafts, which were exploited by the Tapejara for soaring [38, 39]. Tapejara probably exploited thermal soaring over vast open expanses of the Araripe Basin around the equatorial belt to boost its gliding performance in the same manner as modern seabirds.

Once within a thermal, Tapejara could circle and climb vertically within the rising column as long as the upward speed of the thermal is greater than the sinking speed of the animal. As it reached the top of the thermal, it could glide straight to an adjoining thermal and gained height by riding the rising air. Because of its low wing loading and low sinking speed, Tapejara had excellent soaring
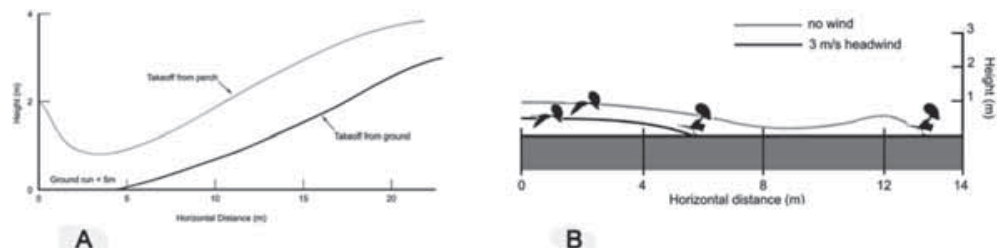

B

Figure 9: The takeoff and landing of Tapejara. (A) The takeoff from a perch needed a certain height $(\sim 2 \mathrm{~m})$ from which to launch safely. Tapejara loses height first and then sweeps up, initiating a 'phugoid' oscillation, but it is minimized by the use of a simulated pitch damper. Tapejara was able to take off from the ground almost instantaneously from a bipedal running position at a distance of $<5 \mathrm{~m}$. (B) The landing mode of Tapejara with 3 $\mathrm{m} / \mathrm{s}$ speed; the touchdown distance with a headwind was $7 \mathrm{~m}$ and without a headwind was $12.5 \mathrm{~m}$. The approach gliding air speed was chosen to be $7 \mathrm{~m} / \mathrm{s}$ and the still air angle of descent is $-3.36^{\circ}[30]$. 
capability in thermals by turning in circles (Fig. 8C). Since the updraft within a thermal is greatest at its center, Tapejara must be capable of maintaining continuous turns of short radius in order remain within the thermal core. To glide without power in circles within a thermal, the wings of Tapejara must be banked, but while increasing the bank angle can tighten the turn, airspeed must increase to avoid stalling in high g-turns.

Using ANFLTSIM we have analyzed the turning performance of Tapejara with fully extended non-flapping wings. Figure $8 \mathrm{D}$ shows three curves for $30^{\circ}, 45^{\circ}$, and $60^{\circ}$ bank angles. As the bank angle increases, the total lift is also increased so that the vertical component remains equal to the weight ( $\mathrm{Mg}$ in newtons). At a $30^{\circ}$ bank angle, the turn radius was $\sim 1.6 \mathrm{~m}$ and the sinking speed in still air was $0.6 \mathrm{~m} / \mathrm{s}$, which is sufficient for Tapejara to remain aloft in typical oceanic thermals, and may have updrafts of $\sim 1 \mathrm{~m} / \mathrm{s}$ or more. The cranial crest may have enhanced the turning performance, especially at the start of the turn while the wing banked rapidly. Tapejara could exploit the meandering 'thermal street' of the equatorial belt from the Araripe Bay to the Atlantic Sea.

\subsection{Takeoff and landing}

Because of its small size and large muscle power, takeoff and landing maneuvering were not difficult for Tapejara (Fig. 5a). No-wind takeoff paths for Tapejara during takeoff (Fig. 10A) were generated

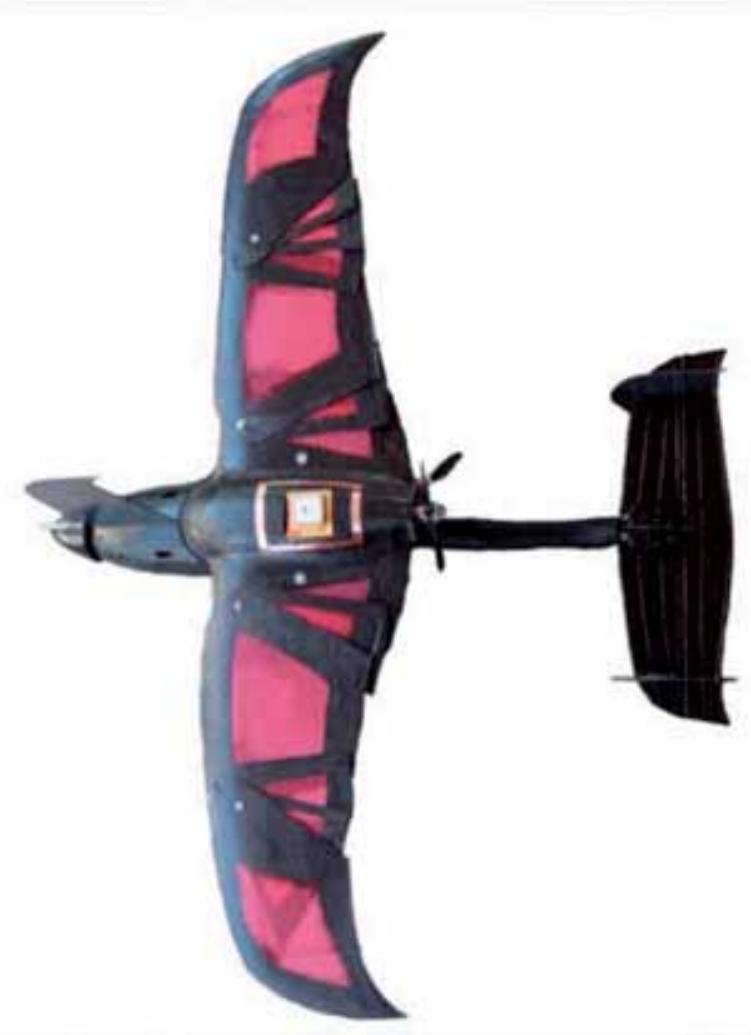

Figure10: The first phase of Pterodrone, a remote-controlled flying robot with a cranial crest (a forwardly placed vertical tail) and a flexible wing. 
using ANFLTSIM. Using a maximum continuous power $(5.6 \mathrm{~W})$, takeoff from a perch needed a certain height $(\sim 2 \mathrm{~m})$ from which to launch safely. The initial launch speed was set at $2 \mathrm{~m} / \mathrm{s}$ (horizontal) as in perching bird [33]. Tapejara loses height at first and then sweeps up, initiating a 'phugoid' oscillation that is suppressed by pitch damping [20, 30,33]. Its equilibrium climb angle is $9.7^{\circ}$ and the equilibrium climb speed is $5.7 \mathrm{~m} / \mathrm{s}$. The ground takeoff speed was calculated assuming the same power $(5.6 \mathrm{~W})$ and same momentum wake deflection $\left(6^{\circ}\right)$ as for the tree launch. Lift-off occurred after a ground run of $\sim 4 \mathrm{~m}$ and reached the same equilibrium speed $(5.7 \mathrm{~m} / \mathrm{s})$ and climb angle $\left(9.7^{\circ}\right)$ (Fig. 9A). However, small pterosaurs such as Eudimorphodon, Rhamphorhynchus, Pterodactylus, and Dorygnathus (mass $<250 \mathrm{~g}$ ) were capable of vertical takeoff and landing [20].

For Tapejara, landing on a solid ground had its hazards, but it had several means of dissipating kinetic energy from an initial flat gliding approach of $\sim 7 \mathrm{~m} / \mathrm{s}$ to a safe touchdown speed. It could use its webbed feet [7] and forewing as air brakes or decrease the speed by pitching up toward highdrag stalling before touchdown. ANFLTSIM trials indicate that in still air it would land at a distance of $\sim 13 \mathrm{~m}$ with a speed of $3 \mathrm{~m} / \mathrm{s}$, which is safe for landing, and in a headwind of $3 \mathrm{~m} / \mathrm{s}$ the touchdown distance is $\sim 6 \mathrm{~m}$ at $2 \mathrm{~m} / \mathrm{s}$ (Fig. 9B). Taking off and landing on water should have been possible, probably similar to ducks of the same size, using long webbed feet for surface running, and skidding to a stop during landing. The animation of takeoff and landing of Tapejara can be viewed at http://vimeo.com/54105788.

\section{BIOMIMICRY FOR PTERODRONE}

We have taken one of the biggest challenges to develop a bio-inspired robotic vehicle, named Pterodrone, which is swift and maneuverable, capable of aerial, terrestrial, scansorial, and aquatic locomotion for use in surveillance $[8,9,40,41]$. In the past few years, extremely lightweight materials and ultra-miniaturized motors and actuators have become available. These tiny components allow engineers to build complex robots on the same scale as flying animals. A primary interest is the scalability of vehicle size. The range of missions for which a UAV may be designed can range from high-altitude environments to urban environments to indoor environments. The variations in size and speed required for the platforms across these environments are not accompanied by an easy scaling of aerodynamics. The mechanisms associated with propulsion for the flapping of birds, bats, and insects are well known to be limited to a small range of Reynolds' number as is the associated range of missions.

\subsection{Baseline shape of the Pterodrone for flight}

A baseline shape is determined for the Pterodrone. This baseline shape of the Pterodrone with a forward placed vertical tail is shown in Fig. 10. This remote-controlled stable aircraft vehicle with flexible wings has demonstrated a flight capability of an agile UAV with the capability of tight turning.

This project presents a revolutionary change in vehicle design by demonstrating configurations that have never been flown. Specifically, the location of the vertical tail of the Pterodrone, mimicking the cranial sail of Tapejara, will range far beyond the standard placements. Consider that the vast majority of the aircraft either have the vertical tail pointing out the top of the rear fuselage or have no tail whatsoever; conversely, Pterodrone will include a vertical tail that can slide forward/backward along the fuselage and up/down through the nose as shown in Fig. 11.

The purpose of a vertical tail is a critical element of any aircraft design. The traditional placement of a vertical tail that points up is chosen to provide the static stability in both roll and yaw axes. A tailless vehicle lacks that stabilizing contribution; therefore, the wing sweep is increased to provide a stabilizing influence on the roll and yaw. In each case, the design is focused on stability. 


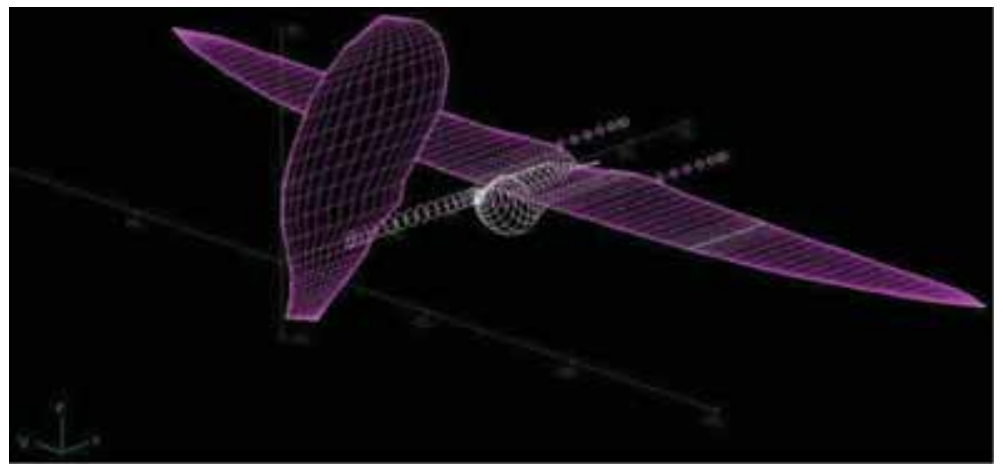

Figure 11: The configuration of Pterodrone with a vertical tail at the nose mimicking the cranial crest of Tapejara [8].

By morphing and repositioning the vertical tail of Pterodrone to resemble the cranial crest of Tapejara, we have shown that the aircraft's turn radius can be reduced by $14 \%$. This improvement is due to the fact that the conventional position of the tail requires the nose of the aircraft to point away from the direction of the turn, while the position of the tail on the aircraft's nose requires the nose to point into the direction of the turn. Pterodrone, with this novel forward-placed tail, will in fact focus on agility as its metric for design. As such, the vertical tail will be placed to enhance the mission performance rather than the static stability. This tradeoff between the performance and stability is certainly well known in the design community; hence, morphing provides an ability to alter that tradeoff during flight. In this model, the tail could not only range across the entire fuselage of the aircraft but also rotate about its leading edge by $45^{\circ}$.

\subsection{Articulated, flexible wings}

A set of multi-jointed wings is critical to enabling mission capability for the Pterodrone. Certainly these flexible wings are essential to optimize flight performance; however, they are equally critical to achieve multiple modalities of locomotion such as walking and sailing. The existing platforms designed by the research team that use limited types of joints will be leveraged to rapidly design the novel vehicle for this project. In each case, a pair of joints is incorporated, which are similar in nature to a shoulder and elbow.

The vertical angle of the wings can be altered by rotating about a pair of joints at the inboard and mid-span locations. These joints allow independent change in the dihedral angle for both the inboard and outboard sections on each wing. The pair of joints in fact allows a wide range of configurations as shown in Fig.12.

The horizontal angle of the wings can also be altered using these joints. This angle, known as the sweep, is varied independently on the left and right wings for both the inboard and outboard. Some representative configurations shown in Fig. 13 demonstrate the range that can result from this multi-joint concept.

\subsection{Multimodal locomotion}

\subsubsection{Flight dynamics}

To examine the effects of the vertical tail placement in Pterodrone, Athena Vortex Lattice (an aerodynamics prediction code created by Mark Drela at MIT) was used to find the trim conditions 
of an Micro Air Vehicle (MAV) model [42]. For simplicity, the model used was a previously studied and successfully flown aircraft [43]. The only alterations were made on the vertical tail, making it a simple rectangle with the same surface area as the original and adjusting its vertical and longitudinal placement. Furthermore, results were found at a wide range of velocities, so that the results could be normalized to the velocity that it would require creating $2 \mathrm{~N}$ of drag on the aircraft. In this manner the performance effects could be compared assuming a constant power plant that could provide only a maximum of $2 \mathrm{~N}$ of thrust. Additional analysis showed similar results for a constant power model of propulsion that is common for propeller systems [8, 43].

\subsubsection{Agile turning}

By morphing and repositioning the Pterodrone's vertical tail to resemble the cranial crest of Tapejara, we have shown that the aircraft's turn radius can be reduced by $14 \%$ [8]. The ability to make
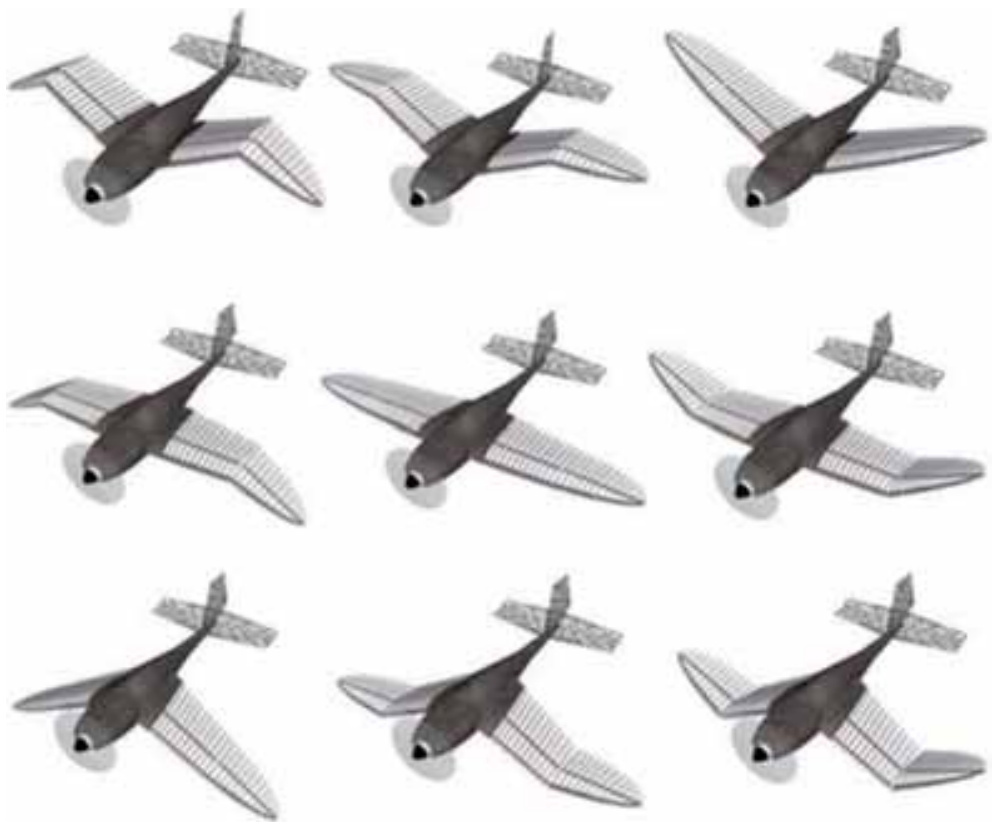

Figure 12: The variations in dihedral.
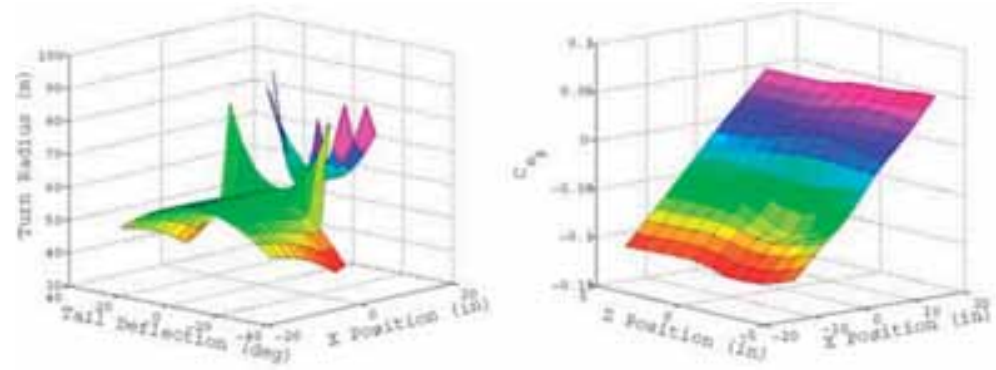

Figure 13: The reduction in the turn radius as the vertical tail is deflected when placed forward of the center of mass, but accompanied by instability in yaw. 
sharper turns is especially important for a small UAV that operates in constrained spaces of urban environments and in the presence of obstacles. The results show a marked improvement in the allowable turning radius when flight conditions are normalized to a constant drag. The results from this code also include the changes in the sideslip angle, angle of attack, and body axis stability derivatives. The vertical tail has a significant effect on turning; consequently, varying the location of that tail will vary the turn characteristics, which are obviously critical to agile maneuvering. In particular, a smaller radius turn and, correspondingly, a higher rate of turn can directly correlate to operating among denser obstacles. A tight turning radius might be the secret weapon of Pterodrone, changing directions abruptly and slowing down quickly (Fig. 14).

As expected, the derivatives show the appearance of lateral instability with a forward-placed vertical tail, but such instability can be controlled using the modern control techniques while the vehicle could still benefit from the improved maneuverability resulting from unstable dynamics.

\subsubsection{Sensor pointing capabilities}

Additional aerodynamic analysis of wing configurations in conjunction with a forward-placed vertical tail demonstrates a phenomenon by which the ailerons and morphing could be used to compensate for a vertical tail deflection.

The combination of morphing and aileron deflection allows the vehicle to compensate for both the roll and yaw moments produced by an offset vertical tail deflection. If the vertical tail position is allowed to vary in both the longitudinal and vertical directions, then the surfaces could be used together in greater combinations to produce a wider variety of trimmed conditions. Increased freedom of trimmed flight conditions could thereby yield a vehicle with a greater ability to point a vehicle-fixed sensor towards the region of interest.

\subsubsection{Walking dynamics}

We have mimicked the quadrupedal locomotion of pterosaurs that favors simplicity of implementation. Pterosaurs have a wing and leg structure consisting of three long segments, namely the humerus/ femur, ulna/tibiotarsus, and manus/pes, and three joints, namely the shoulder/hip, elbow/knee, and knuckle/ankle. During standing, the three joints in pterosaurs are somewhat flexed. By alternate flexing and extending these joints, the animal moves (Fig. 15). The leg design of walking and hopping robot is usually described by the spring-loaded inverted pendulum model [44].

In this walking robot, rigid mechanics with joint actuators represent the musculoskeletal system and stability is established with multiple sensory feedbacks from lumbosacral plexus and closed-loop controls. Thus, the first generation design attempts to retain as many of the advantages of walking as
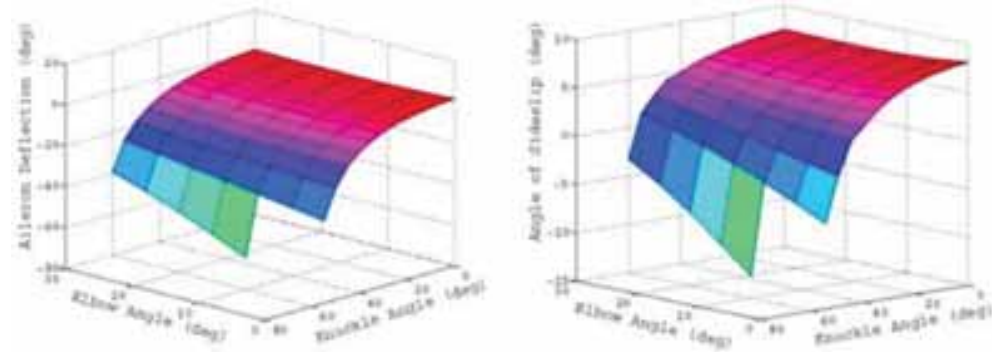

Figure 14: Trimming at various sideslip angles using wing sweep and aileron deflection with a fixed vertical tail deflection. 


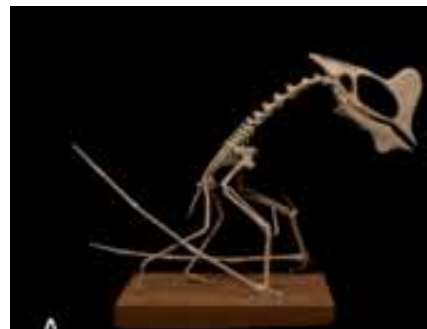

A
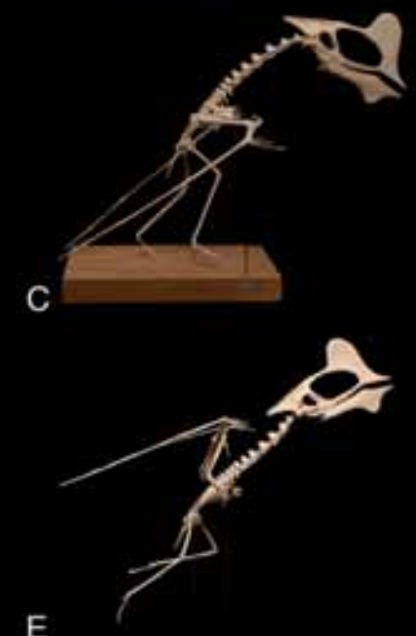

$\mathrm{E}$

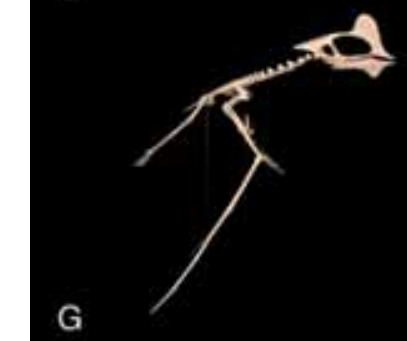

B

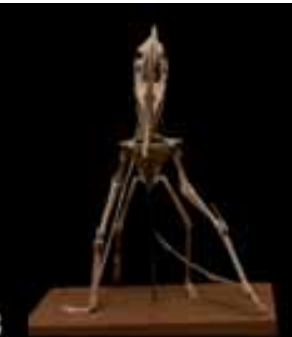

D
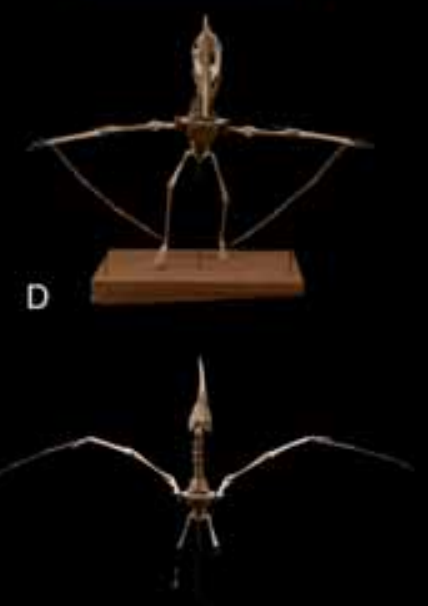

F

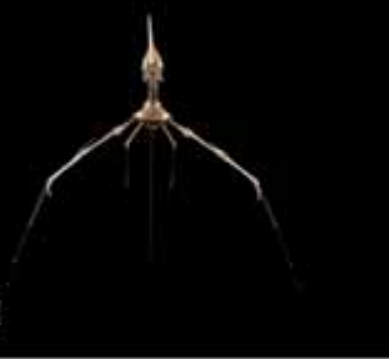

Figure 15: Flight-initiating jumping and takeoff sequence of Tapejara from quadrupedal running to bipedal running, using hindlimbs as a catapult. For Pterodrone, standing takeoff powered by the hindlimbs would be possible.

possible while incorporating parts with multiple utilities to reduce the complexity. This design requires only three joints on each limb and weight to a minimum. Three rotational actuators can be placed at these three joints, which control the direction of the jumps, and linear actuator at the base of the manus and foot that controls the height of the footfall. The manus and foot would be useful during terrestrial locomotion by conferring grip and stability. The forelimbs could be morphed into wings, and collapsible legs can be retracted during flight similar to the landing gear of an aircraft.

The most crucial maneuvers in pterosaur flight are takeoff and landing. Ground takeoff takes more energy than does level flight because the pterosaur must accelerate and climb. Small pterosaurs could take off instantly from the ground without running, but larger pterosaurs need speed to become airborne. The pterosaur must beat its wings vigorously to obtain its lift. Both hindlimbs and wings 
of Pterodrone contribute to take off from the ground. During hindlimb-driven takeoff, the Pterodrone moves from a standing position into a crouch, lowering its CG; the two feet reposition parallel to each other, while the wings remain folded. As the hindlimbs extend, the feet push the ground to initiate jumping for takeoff. Once in the air, the engine would provide the thrust and the extended wings the required lift to remain aloft.

Small pterosaurs could jump to the air during ground takeoff using the legs as the catapult. All jumping involves the application of force against a substrate, which in turn generates a reactive force that propels the jumper away from the substrate. For flight-initiating jump, a pterosaur undergoes several postural changes as it vaults over the hindlimbs and using flapping to gain altitude. The launch sequences include stance, crunch, vault, launch, liftoff, upstroke, and downstroke. The main design for the flight-initiating jumping mechanism is a lightweight propulsion unit for the Pterodrone. The three-element limbs of Pterodrone are well suited for jumping into the air allowing vertical takeoff and landing. The basic components of the design are the three bar leg mechanism that is connected to the fuselage and is actuated via the input link using a torsion spring.

Several methods of terrestrial locomotion could be implemented in the design $[45,46]$. The first-generation design favors simplicity of implementation over locomotive speed. Building a pure walking robot requires many joints, increasing the complexity of the design and movement and the weight of the vehicle, thereby making the flight and sailing much more difficult. Thus, the first-generation design attempts to retain as many of the advantages of walking as possible while incorporating parts with multiple utilities to reduce the complexity. This design requires only two joints on each wing (shoulder and elbow) keeping the complexity and weight to a minimum. The design also uses the rear wheels that are necessary for takeoff and the morphing head position used for improved flight control as integral parts of its walking motion.

The first design uses wheels in the rear of the vehicle and morphs its wings to walk on its 'elbows.' During walking the shoulder joint permits the arms to move along the direction in which the vehicle is pointed [20]. Thus, the walking motion is more akin to a soldier crawling on his elbows and dragging his legs behind. In this sense, the design continues a biological-inspired approach since natural systems such as the pterosaurs also use joints for walking. The concept designed for this vehicle adopts the pterosaur-inspired approach as shown in Fig. 16. Eventually, hand and feet would replace the wheels as in pterosaurs for terrestrial and aquatic locomotion as the design improves (Fig. 17). Wheeled UAVs need to have all wheels in contact with the ground all the time during terrestrial locomotion. In contrast, legged animals keep only some legs in contact with the ground at any given time during progression. For certain types of rough terrain and a large number of obstacles, legged vehicles have advantages over wheeled vehicles.

The hindlimbs of Pterodrone are also used for landing gear, which is equipped with suspension and breaking systems to support the full force of landing and bring it quickly and safety to a halt. Both pterosaurs and birds have already solved the problem of perching on small surfaces, using wing morphing and flapping techniques. Combining these aspects of flight and locomotion into a fully actuated, intelligent Pterodrone would be the ultimate goal with capability of flapping flight.

\subsubsection{Wing folding and flapping dynamics}

The mechanism for spreading and folding wings in birds and pterosaurs is very neat by manipulating the joints of the wing elements. Unlike the pterosaur's wing membranes, which are an encumbrance when folded around the body, bird's wings can be folded instantly by fully flexing the elbow and wrist joints. The bird's wing is different, in that it does not depend on tensioning a flexible membrane by the legs; the radiating, stiff shafts of the flight feathers carry the aerodynamic forces on the wing. Although a certain degree of flexibility is permissible in a wing, an animal cannot fly if its wings lack 

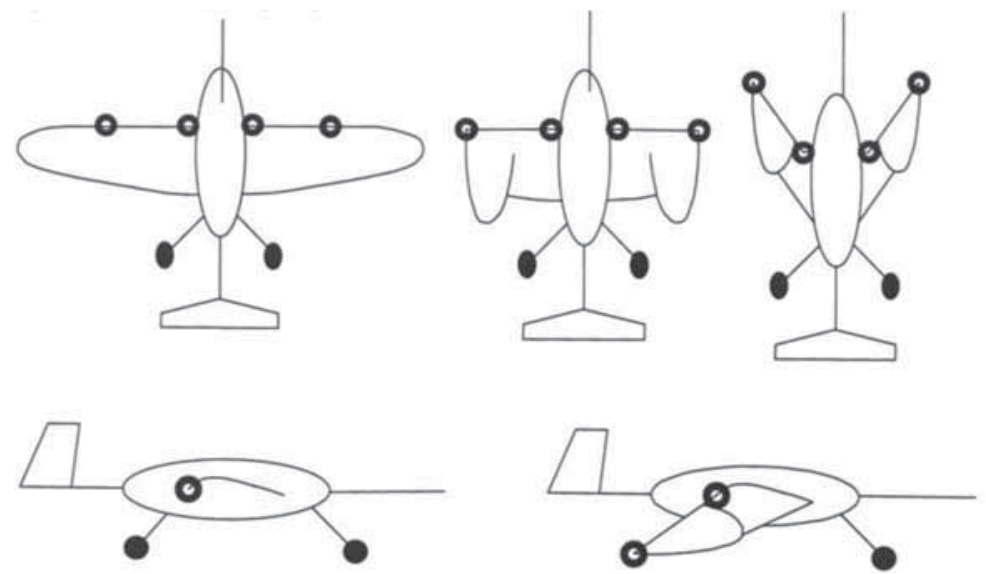

Figure 16: The top view (top) and side view (bottom) of the flight to walking stance transformation.
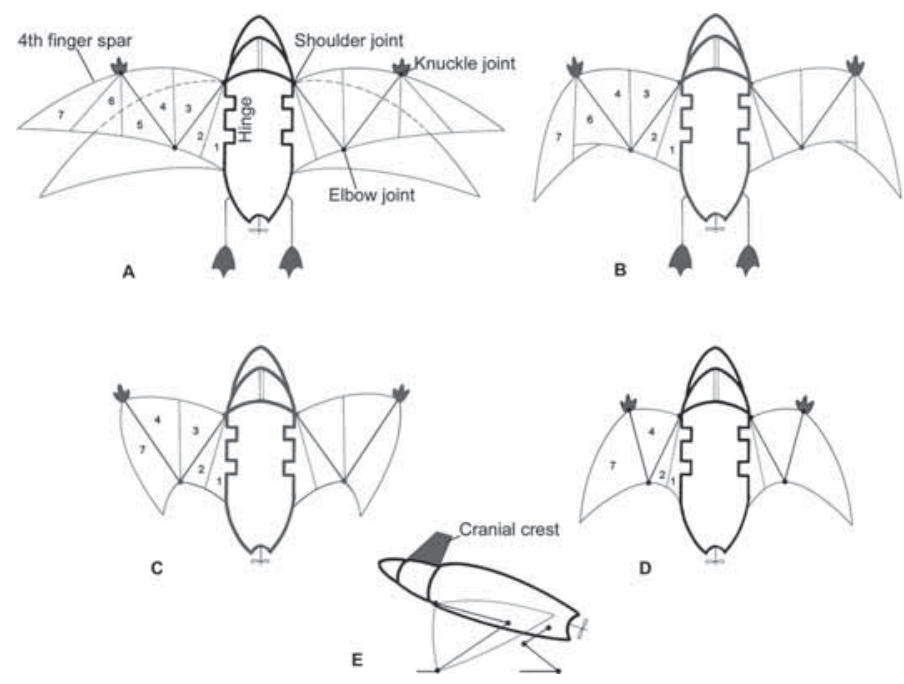

Figure 17: (A-D) The wing-folding mechanism of Pterodrone. Seven overlapping winglets (numbered here as 1-7) are shown in dorsal views at three joints during wing morphing - knuckle, elbow, and shoulder joints - as the wing transforms from flight to walking stance. The hinge joint between the wing and the fuselage would allow flapping during flight, as well as folding of the wing against the body during walking. (E) Pterodrone in quadrupedal posture in the side view, where the wings are folded against the body.

stiffness. Birds achieve stiffness through the rigidity of feathers and pterosaurs by actinofibrils. Feathers have the advantage over the membranous wings of pterosaurs because they give the wing a modular construction, which limits the damage. At rest, the wing can be folded into a compact $\mathrm{Z}$ against the body, out of harm's way, and can be extended just as quickly, ready for instant flight. The feather is an architectural marvel. The asymmetrical design of flight feather gives it a curved, airfoil cross section of aerodynamic design. This arrangement makes the whole wing convex on the dorsal side and concave on the ventral side to its main camber. Each flight feather slides over its neighbor 
on its distal side and under its neighbor on the proximal side. The overlap effect is similar to that of a fanned-out hand of playing cards. Each card by itself bends easily, but when overlapped they are stiff. This arrangement provides the folding and unfolding wing more efficiently and makes the wing surface relatively impermeable to air on the downstroke.

We have opted for bird wings instead of pterosaur wings for designing the Pterodrone to make the wings stiff rather than compliant. For simplicity, we have used only the outer part of the bird's wings in designing Pterodrone, from the wrists to the wing tips supporting the asymmetric primary feathers, called hand sections, which functions primarily as a lifting surface. A propeller in the Pterodrone provides the thrust.

For designing the Pterodrone wings, we have used seven overlapping, feather-shaped winglets (Fig. 17, 1-7) to create a variable-sweep wing that may be swept back and then returned to its original position during flight. Folding the feather on only one wing creates a difference in lift and can turn the Pterodrone right or left. Folding the wings on both sides, the sweepback wing reduces the surface area to allow Pterodrone to dive or fly faster. Soaring can be achieved by spreading the feathers out as far as they will go, increasing the surface area. The variable sweep-wing will be useful for Pterodrone, which is expected to function at both low and high speeds. These artificial feathers are attached to a circular extensor that permits a variable sweep-wing. The horizontal angle of the wings can be altered using this extensor joint. This mechanism also allows folding and unfolding of the wings. The vertical angle of the wings can be altered by rotating about a pair of hinge joints at the inboard and mid-span locations. These joints allow the folded wings to fit snugly against the sides of the Pterodrone, when not in use. In an extended position, this joint may mimic the flapping flight.

The preliminary design of a flapping Pterodrone would be quite different from that of fixed-wing UAV. Flapping Pterodrone could be designed according to the wing actuation mechanisms (motormechanical linkage) into a pterosaur type. A flapping Pterodrone would generate aerodynamic forces and moments to fly and maintain its stability by a complex multi-degree of freedom of wing motion: flapping, pitching, twisting, and lagging (Fig. 17).

\subsubsection{Sailing dynamics}

Pterosaurs could glide on the water surface in the downwind direction where the cranial sail in conjunction with two upright outer wings performed like a three-masted sailboat (Fig. 18). The cranial sail might have served as a jib and a front rudder to steer the animal [40] as the ventral surface of the animal is rounded and streamlined without any keel or hull, and the inner wings and hindlimbs served as multihulls and stabilizers similar to those catamarans [47]. The wing action of pterosaur is used to model the aquatic Pterodrone. Paleontologists have long noted that pterosaur wings were similar to sails, being membranes that could flex in either direction. The resemblance may prove to be more than passing: our research suggests that the piscivorous reptiles sailed the seas as well as the skies during their extended reign for 160 million years [41]. We reconstructed the sail and cranial crest of Tapejara and made a series of models to examine its motion and then analyzed its aerodynamics and hydrodynamics with a biomechanical computer simulation. The sails of Tapejara resemble those of a two-masted schooner with a jib where the huge membranous head crest functions like a jib. The basic design of Tapejara is a cross between Wiebel (triple wind-surfing boards) and a two-masted schooner. Wiebel is the fastest sailboat in the world. Its hull has catamaran-like design with two lateral surfboards and a central aft surfboard. The hull of Tapejara resembles that of a Wiebel with a trimaran design. The sternum of Tapejara resembles the central surfboard, which is positioned forward, whereas the two legs represent lateral surfboards. Thus the reptile's sternum and legs would have contacted the water much as a trimaran's hulls do. Tapejara could glide across the surface with minimal effort, keeping their wings upright to catch a breeze, probably for short distances between bouts of fishing. 
For all types of hulled craft, the first design concern is the roll stability of the craft while submerged. The most important stability measure is a comparison between the heeling and righting moments. However, the current design has no aerodynamic surface above the water; consequently, very little heeling moment would be created, even in a stiff wind. Thus, the righting arm curve can be analyzed as a good indicator of the craft's stability as shown in Fig. 19. The stability can be augmented using a pair of methods. The first is to lower the CG so that the heavy components such as the batter are lower

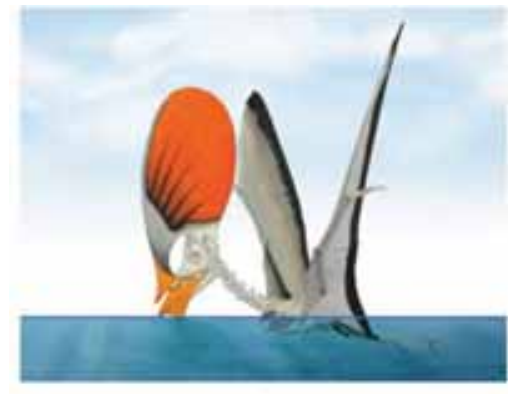

A

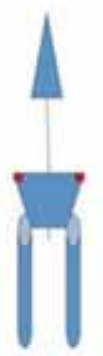

B

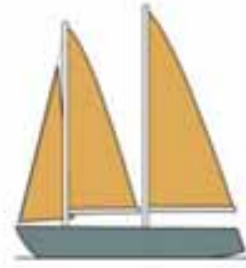

C

Figure 18: (A) The restoration of a sailing Tapejara that mimics a two-masted schooner where the cranial sail acts like a jib. Tapejara could sail faster than the prevailing wind during foraging in upwind sailing by keeping the wings in upstroke position. (B) The hull of Tapejara had a catamaran design. (C) The sails of Tapejara resemble those of a twomasted schooner with a jib.
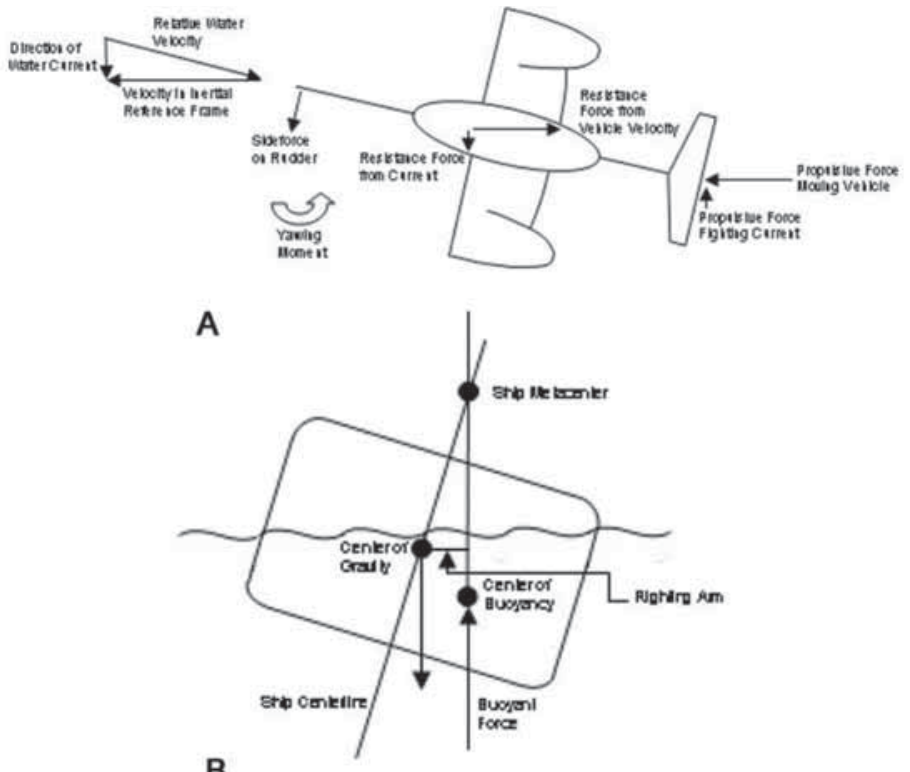

Figure 19: The sailing dynamics. (A) The balance between forces and moments. (B) The stability analysis. 
to create a larger righting moment. The second method increases the hull size to increase the residual buoyancy moment. The morphing wings could also balance the vehicle, in a way that ships cannot, by morphing the wings to move the $\mathrm{CG}$, thus increasing the righting moment.

Once the design is proven stable, then the performance will be analyzed, with the maximum relative speed, acceleration, and turning rates being the most important. The associated forces and moments used in determining the performance are shown in Fig. 19. Note that the propeller remains out of the water to avoid inefficiencies with submerged propulsion.

\section{DISCUSSION AND CONCLUSION}

Two volant archosaurs, pterosaurs and birds, acquired flight during the Mesozoic era. Although the aerodynamics of bird flight have been studied extensively since the time of Leonardo da Vinci, the pterosaur flight performance is poorly known because their fossils are usually crushed and flattened in two dimensions and difficult to study. In recent decades, exquisite three-dimensional pterosaur fossil skeletons have been found from the Early Cretaceous of Brazil along with a soft tissue preservation, which provide critical insights into their flight capabilities $[6,15,30]$. Pterosaurs were the dominant aerial vertebrates during the 'Age of Dinosaurs' and experimented successfully with wings, kinematics, aerodynamics, control, and sensory systems for 160 million years. Some advanced pterosaurs such as male pterodactyloids sported a large cranial crest for sexual display, but its puzzling aerodynamic function for control sheds new light on the future aircraft design. Tapejara was a medium-sized pterodactyloid with a large cranial crest that lived along the mountainous coast of Brazil during the Early cretaceous ( 110 million years ago). Computer simulation of the flight performance of Tapejara suggests that it was a highly mobile flyer with a level flight speed range of $9-47 \mathrm{~km} / \mathrm{h}$. At speeds lower than its most efficient cruise speed $(27 \mathrm{~km} / \mathrm{h})$ there is a wide gap between the estimated aerobic minimum power available $(5.6 \mathrm{~W})$ and the minimum power required for a steady level flight $(\sim 2 \mathrm{~W})$, permitting high maneuverability. For the same reason, takeoff at full power was almost instantaneous after running to a ground speed of $4 \mathrm{~m} / \mathrm{s}$. Tapejara was an excellent glider and probably exploited thermal soaring. The oversize cranial crest with a soft-tissue extension acted like a forward-placed vertical tail of an aircraft that enhanced the tight turning within a thermal.

We only learn to appreciate the flight dynamics of pterosaurs when we try to imitate it. Mimicking the body plan and flight of Tapejara to build an autonomous UAV called Pterodrone, morphing technology enables us to adapt its shape to best suit the flight condition, thereby enhancing the mission performance. We are mimicking the wing movement of pterosaurs to help improve the maneuverability of Pterodrone. Studying the flight dynamics of pterosaurs leads us to a new generation of autonomous, sensor-packed UAV that navigates more effectively in tight places. Pterodrone is a bioinspired model, which provides essential support to human task forces in situation assessment and surveillance of confined, obstacle-cluttered airspace of urban setting. Adding a forwardly placed vertical tail to the nose of the aircraft, mimicking the cranial crest of Tapejara, Pterodrone can reduce the turn radius by $14 \%$. The ability to make sharper turns is especially important for small aircraft that operates in urban environments and in the presence of obstacles. The morphing capability of the vertical tail allows it to vary its position during flight. Multimodal locomotion of Pterodrone offers a great adaptability to perform effectively in different operating regimes in the complex urban surveillance mission. Pterodrone is similar in scale to a seagull: about $60 \mathrm{~cm}$ long with a wingspan of $150 \mathrm{~cm}$ and has a similar but simpler wing morphing capability and airfoil characteristics. By watching how seagulls alter their wing shape and using the morphing techniques, the agile Pterodrone can squeeze through confined spaces, such as alleyways, and change the direction rapidly. It could automatically find its way to monitor locations, such as apartment blocks, where suspicious 
activity is detected. The ultimate aim of Pterodrone is to have an on-board autopilot so that it can fly itself through cities to search for bioagents, explosives, or other hazards. The aircraft will need to identify unexpected obstacles, re-plan the flight, and go on with the mission.

\section{ACKNOWLEDGMENTS}

The authors thank Carlos A. Brebbia for inviting us to contribute this paper and Texas Tech University and University of Florida for continued support in our research. The authors thank Bill Mueller and Mike Nickell for preparing the illustrations, Larry Witmer and R. Jack Templin for discussion and insights, Alex Kellner for providing a three-dimensional cast skeleton of Tapejara, and an anonymous reviewer for helpful comments and suggestions.

\section{REFERENCES}

[1] RQ-11 Raven Unmanned Aerial vehicle, United States of America, available at www.armytechnology.com/projects/rq11-raven/

[2] Abdulrahim, M., Garcia, H. \& Lind, R., Flight characteristics of shaping membrane wing of a MicroAir vehicle. Journal of Aircraft, 42, pp. 131-137, 2005. doi: http://dx.doi.org/ $\underline{10.2514 / 1.4782}$

[3] Bahlman, J.W., Swartz, S.M. \& Breuer, K.S., Design and characteristic of a multi-articulated robotic bat wing. Bioinspiration and Biomimetics, 8, 2013. doi: http://dx.doi.org/10.1088/17483182/8/1/016009

[4] Lambrecht, B.G.A., Horchler, A.D. \& Quinn, R.D., A small insect inspired robot that runs and jumps. Proceedings of the International Conference On Robotics and Automation, ICRA: Barcelona, Spain, pp. 33-48, 2005.

[5] Wellnhofer, P., The Illustrated Encyclopedia of Pterosaurs, Crescent Books: New York, 1991.

[6] Unwin, D.M., Pterosaurs from Deep Time, PI Press: New York, 2006.

[7] Maynard Smith, J., The importance of nervous system in the evolution of an animal flight. Evolution, 6, pp. 127-129, 1952. doi: http://dx.doi.org/10.2307/2405510

[8] Roberts, B., Lind, R. \& Chatterjee, S., Flight dynamics of a pterosaur-inspired aircraft utilizing a variable-placement vertical tail. Bioinspiration and Biomimetics, 6, p. 026010, 2011. doi: http://dx.doi.org/10.1088/1748-3182/6/2/026010

[9] Chatterjee, S., Roberts, B. \& Lind, R., Pterodrone, a pterodactyl-inspired unmanned air vehicle that flies, walks, climbs, and sails. WIT Transactions on Ecology and the Environment, 138, pp. 301-316, 2010. doi: http://dx.doi.org/10.2495/DN100261

[10] Bennett, S.C., Sexual dimorphism of Pteranodon and other pterosaurs with comments on cranial crests. Journal of Vertebrate Paleontology, 12, pp. 422-434, 1992. doi: http://dx.doi.org/ $\underline{10.1080 / 02724634.1992 .10011472}$

[11] Lü, J., Unwin, D.M., Deeming, D.C., Jin, X., Liu, Y. \& Ji, Q., An egg-adult association, gender, and reproduction in pterosaurs. Science, 331, pp. 321-324, 2011. doi: http://dx.doi. org/10.1126/science.1197323

[12] Campos, D.A. \& Kellner, A.W.A., Short note on the first occurrence of Tapejaridae in the Crato member (Aptian), Santana Formation, Araripe Basin, northeastern Brazil. Anais da Academia Brasileira de Ciencias, 60, pp. 459-469, 1997.

[13] Martill, D.M. \& Naish, D., Cranial crest development in the Azhdarchoid pterosaur Tupuxuara, with a review of the genus and tapejarid monopholy. Palaeontology, 49, pp. 925-941, 2006. doi: http://dx.doi.org/10.1111/j.1475-4983.2006.00575.x

[14] Eaton, G.F., Osteology of Pteranodon. Memoir of Connecticut Academy of Science, 2, pp. 1-38, 1910. 
[15] von Kripp, D., EinLebensbild von Pteranodonlongiceps auf flugtechnischerGrindlage. Nova ActaLeopoldina NF, 12, pp. 215-246, 1943.

[16] Frey, E., Tischlinger, H., Buchy, M.C. \& Martill, D.M., New specimens of Pterosauria (Reptilia) with soft parts with implications for pterosaurian anatomy and locomotion. Evolution and Paleobiology of Pterosaurs, eds E. Buffetaut \& J.M. Mazin, Special Publications: London, Geological Society, 217, pp. 233-266.

[17] Stein, R.S., Dynamic analysis of Pteranodonlongiceps: a reptilian adaptation for flight. Journal of Paleontology, 49, pp. 534-548, 1975.

[18] Kellner, A.W.A. \& Campos, D.A., The function of the cranial crest and jaws of a unique pterosaur from the Early Cretaceous of Brazil. Science, 207, pp. 389-392, 2002. doi: http:// dx.doi.org/10.1126/science.1073186

[19] Sibley, D.A., The Sibley Guide to Birds, Alfred A. Knopf: New York, 2000.

[20] Chatterjee, S. \& Templin, R.J., Posture, locomotion, and paleoecology of pterosaurs. Geological Society of America, Special Paper, 376, pp. 1-64, 2004.

[21] Jantzen, B. \& Eisner, T., Hindwings are unnecessary for flight but essential for execution of normal evasive flight in Lepidoptera. Proceedings of the National Academy of Sciences USA, 105, pp. 16636-16640, 2009. doi: http://dx.doi.org/10.1073/pnas.0807223105

[22] Witmer, L.A., Chatterjee, S., Franzosa, J. \& Rowe, T., Neuroanatomy of flying reptiles: implications for flight, head posture, and behavior of pterosaurs. Nature, 425, pp. 950-953, 2003. doi: http://dx.doi.org/10.1038/nature02048

[23] Dudley, R., The Biomechanics of Insect Flight, Princeton University Press: Princeton, New Jersey, 2000.

[24] Brown, R.E. \& Fedde, M.R., Airflow sensors in the avian wing. Journal of Experimental Biology, 179, pp. 13-30, 1993.

[25] Alexander, D.E. Nature's Flyer, Johns Hopkins University Press: Baltimore, 2002.

[26] Sterbing-D’Angelo, S., Chadha, M., Chiu, C., Falk, B., Xian, W., Barcelo, J. \& Zook, J.M., Bat wing sensors support flight control. Proceedings of the National Academy of Sciences, 108, pp. 11291-11296, 2011. doi: http://dx.doi.org/10.1073/pnas.1018740108

[27] Goulding, M., Circuits controlling vertebrate locomotion: moving in a new direction. Nature Reviews Neuroscience, 10, pp. 507-518, 2009. doi: http://dx.doi.org/10.1038/nrn2608

[28] Pondvai, E. \& Hone, D.W.E., New models for the wing extension in pterosaur. Historical Biology, 20, pp. 237-254, 2008. doi: http://dx.doi.org/10.1080/08912960902859334

[29] Palmer, C. \& Dyke, G.J., Biomechanics of the unique pterosaur pteroid. Proceedings of the Royal Society of London B, 279, pp. 1218-1224, 2009. doi: http://dx.doi.org/10.1098/rspb.2011.1529

[30] Chatterjee, S. \& Templin, R.J., The flight dynamics of Tapejara, a pterosaur from the Early Cretaceous of Brazil with a large cranial crest. Acta Geologica Sinica, 86, pp. 1377-1388, 2012. doi: http://dx.doi.org/10.1111/1755-6724.12007

[31] Prandtl, L. \& Tietjans, O.G., Applied Hydro- and Aerodynamics, McGraw-Hill: New York, 1934.

[32] Stepniewski, W.Z. \& Keys, C.M., Rotary-Wing Aerodynamics, Dover Publications: New York and Minneola, 1984.

[33] Templin, R.J., The spectrum of animal flight: insects to pterosaurs. Progress in Aerospace Sciences, 36, pp. 393-436, 2000. doi: http://dx.doi.org/10.1016/S0376-0421(00)00007-5

[34] Tucker, V., Energetic cost of locomotion of animals. Comparative Biochemistry and Physiology, 34, pp. 841-846, 1970. doi: http://dx.doi.org/10.1016/0010-406X(70)91006-6

[35] Pennycuick, C.J., Thermal soaring compared in three dissimilar tropical bird species, Fregata magnificens, Pelecanus occidentalis and Coragyps atratus. Journal of Experimental Biology, 102, pp. 307-325, 1983. 
[36] Woodcock, A.H., Convection and soaring over the open sea. Journal of Marine Research, 3, pp. 248-253, 1940.

[37] Weimerskirch, H., Chastel, O., Barbraud, C. \& Tostain, O., Frigatebirds ride high on thermals. Nature, 21, pp. 333-334, 2003. doi: http://dx.doi.org/10.1038/421333a

[38] Masey, J.G. (ed.), Santana Fossils: An Illustrated Atlas, T. F. H. Publications: New Jersey, 1991.

[39] Scotese, C.R., The Cretaceous: PaleoAtlas for ArcGIS in PALEOMAP Project. University of Texas, Arlington, 2009.

[40] Chatterjee, S., Alexander, D.E., Lind, R., \& Gedeon, A., The sailing performance of the crestedpterodactyloid Tapejara from the Early Cretaceous of Brazil. GSA Abstracts with Programs, 41(7), p. 685, 2009.

[41] Chatterjee, S., Lind, R., Gedeon, A. \& Roberts, B., Pterodactyl-inspired unmanned aerial vehicle with multimodal locomotion. GSA Abstracts with Programs, 40(6), p. 394, 2008.

[42] Drela, M. \& Youngren, H., AVL-aerodynamic analysis, trim calculation, dynamic stability analysis, aircraft configuration development. Athena Vortex Lattice, 3.26, 2000 (available at http://raphael.mit.edu.avl/)

[43] Grant, D.T., Abdulrahim, M. \& Lind, R., Flight dynamics of a morphing aircraft utilizing independent multiple-joint wing sweep. International Journal of Micro Air Vehicles, 2(2), p. 91-106, 2010. doi: http://dx.doi.org/10.1260/1756-8293.2.2.91

[44] Sato, A. \& Buehler, M., A planar hopping robot with one actuator: design, simulation and experimental results. Proceedings of 2004 IEEE/RSJ International Conference on Intelligent robots and Systems, 2004, pp. 3540-3545, 2004.

[45] Alexander, R.M., Exploring Biomechanics: Animals in Motion, W. H. Freeman: New York, 1992.

[46] Todd, D.J., Walking Robots: An Introduction to Legged Robots, Kogan Page Ltd.: London, 1985.

[47] Marchaj, C.A., Aero-Hydrodynamics of Sailing, Dodd, Mead \& Co.: New York, 1979.

This is an enlarged and updated version with new observations of the paper published in WIT Transactions on Ecology and the Environment, Vol 138, ( 2010 WIT Press, www.witpress.com, ISSN 1743-3541 (on-line), doi:10.2495/DN100261. 